\title{
Pressure drop in pipelines due to pump trip event
}

\author{
Y. M. Stokes ${ }^{1}$ \\ A. Miller ${ }^{2}$ \\ G. Hocking ${ }^{3}$
}

(Received 23 November 2015; revised 14 September 2016)

\begin{abstract}
We consider the pressure pulse or surge in a pipeline due to an unplanned sudden shutdown of a pump system in the pipeline network. This is known as water hammer. Our primary focus is the negative pressure pulse that travels downstream from the pump(s), is reflected with a sign reversal from the end, and travels back to the pump(s). As part of the preliminary design of a pipeline it is necessary to determine the minimum head envelope associated with such an event, which is used to determine where surge protection will be needed in the pipeline. Of particular interest is whether the initial head drop at the pump(s) due to a sudden drop of the flow speed to zero, as given by the Joukowski formula, gives a sufficiently accurate prediction of the minimum head at the pump(s). This minimum head is used to construct the minimum
\end{abstract}

DOI:10.21914/anziamj.v57i0.10277, (c) Austral. Mathematical Soc. 2016. Published October 6, 2016, as part of the Proceedings of the 2015 Mathematics and Statistics in Industry Study Group. ISSN 1445-8810. (Print two pages per sheet of paper.) Copies of this article must not be made otherwise available on the internet; instead link directly to the DOI for this article. Record comments on this article via http://journal. austms.org.au/ojs/index.php/ANZIAMJ/comment/add/10277/0 
head envelope for the downstream pipeline. An examination of the relevant literature along with solution of the water hammer equations shows that, assuming the flow speed falls instantaneously to zero at the $\operatorname{pump}(\mathrm{s})$, the total drop in head at the pump(s) is given by the sum of the initial Joukowski head change and the friction loss under normal operating conditions. While the friction loss may not be significant in short pipelines, in long pipelines it cannot be neglected.

\section{Contents}

1 Introduction

2 Preliminary pipeline design

3 Head loss at the pump: the Joukowski formula

4 The water hammer equations

5 Solution of the simplified water hammer equations

M177 5.1 The method of characteristics . . . . . . . . . . M177

5.2 An alternative derivation of Joukowski's formula . . . . . M178

5.3 Numerical solution . . . . . . . . . . . . . . . . . M180

6 Simple examples of pump trip events $\quad$ M183 6.1 A long pipeline example . . . . . . . . . . . . . M183

6.2 A short pipeline example . . . . . . . . . . . . . M195

6.3 An approximation to the additional fall in head at the pump M197 


\section{Introduction}

SunWater presented to MISG the problem of surge in a long pipeline when there is an unplanned sudden shutdown of the pump system, due to a power failure, for example. This is known as a "pump-trip event". When such an event occurs a positive/negative pressure pulse (or surge) travels along the full pipeline network upstream/downstream from the location of the trip event-a phenomenon known as water hammer. The propagation of the initial pressure pulse/surge transmits the signal along the pipe to bring the water to a partial stop. This pulse travels at close to the speed of sound, which is typically around $1000 \mathrm{~m} / \mathrm{s}$ in a water-filled steel pipe. It is often reflected back at various points along its travel path, for example, due to a change in the pipe diameter, and it is reflected back from the pipe outlet.

The phenomenon of water hammer is commonly associated with the rapid closure of a valve or tap. In a household system this may cause some violent shuddering. A description of wave propagation upstream due to closure of a valve downstream of a reservoir is given by Chaudhry [1, §1-5] which, while a different situation to that considered here, is enlightening. A demonstration example of surge due to pump failure in a pumped rising main is given by Thorley $[8, \S 2.2]$. As a pressure pulse travels over the varying topography, the pressure variations can lead to potentially catastrophic damage to the pipeline system [e.g. 1, §1-10]. SunWater advised the group that a check valve is always included just upstream/downstream of a pump, which closes on pump failure to prevent back flow through the pump and any damage to it.

Sunwater was interested in estimating the magnitude of the pressure surges due to a pump-trip event. They were particularly interested in predicting the downstream surge along the pipe and the need for surge protection that this implies, in order to better estimate the cost of the pipeline prior to a full detailed design. In particular, they wished to determine the accuracy of the Joukowski formula for prediction of the magnitude of the pressure drop at the pump(s). 
The group broke the study into several problems for investigation:

- the principal features of the preliminary pipeline design process;

- the early stages of a pump-trip event, including the derivation of Joukowski's formula which is used to estimate the initial hydraulic head loss; and

- solution of coupled PDEs (the water hammer equations) in time and space for pressure and velocity.

The basic mathematical description of water hammer is traceable back to the late 1800s through the work of Korteweg [2], Lamb [3] and Skalak [5]. A brief history on the study of water hammer is given by Chaudhry [1]. Two important names in the field, after whom equations have been named, are Joukowski, whose classic report was first published (in Russian) in 1898, and Allievi who published the general theory of water hammer in 1903 and who is considered to be the originator of the basic water hammer theory with a dynamic equation more accurate than that of Korteweg.

\section{Preliminary pipeline design}

Consider a pipeline extending from a water source at $x=0$, where one or more pumps are located, to a reservoir or outlet at $x=L$; then $x$ is the horizontal distance along the pipe, downstream from the pump(s) (Figure 1). The pump(s) provide the necessary energy to transport water along the pipe. This energy must be sufficient to overcome pipe friction and raise the water from the source elevation to the final elevation (which may be more than a hundred kilometres away and hundreds of meters higher) at a satisfactory flow speed. Neglecting friction losses and assuming a steady flow, the pressure $p(x)$, pipe and ground elevation $z(x)$, and flow speed $V(x)$ at position $x$ along the 
pipeline are related by the Bernoulli equation [6]

$$
\frac{p}{\rho g}+\frac{\mathrm{V}^{2}}{2 \mathrm{~g}}+z=\mathrm{C}
$$

where $\rho$ is the water density, $\mathrm{g}$ is gravitational acceleration and $\mathrm{C}$ is a constant. For a pipe of constant diameter, the flow speed $V$ is constant, otherwise, it is $\mathrm{V}(\mathrm{x})=\mathrm{Q} / \mathrm{A}(\mathrm{x})$ where $\mathrm{Q}$ is the (constant) volume flux along the pipe and $A(x)$ is the cross-sectional area at position $x$. Henceforth we assume that $A$ and the steady flow $V$ are constant along the length of the pipeline. Equation (1) must be modified in the presence of other factors, such as turbulent friction $(f x /(2 g D)) V^{2}$, and other head losses $\beta(x) V^{2} /(2 g)$ due to joins, bends, valves and other pipeline fittings along the pipeline to point $x$ that disturb the flow, so that

$$
C=\frac{p(x)}{\rho g}+\left[1+\beta(x)+\frac{f x}{D}\right] \frac{V^{2}}{2 g}+z(x),
$$

where $D$ is the internal pipe diameter and $f$ is the friction coefficient. At the end of the pipeline the pressure as the water exits the pipe is assumed to be atmospheric, $p_{A}$, which gives the value of the constant

$$
\mathrm{C}=\frac{p_{\mathrm{A}}}{\rho g}+\left[1+\beta_{\mathrm{L}}+\frac{\mathrm{fL}}{\mathrm{D}}\right] \frac{\mathrm{V}^{2}}{2 \mathrm{~g}}+z_{\mathrm{L}}
$$

where $z_{\mathrm{L}}=z(\mathrm{~L})$ and $\beta_{\mathrm{L}}=\beta(\mathrm{L})$. Subtracting (3) from (2) and rearranging gives

$$
\mathrm{H}(x)=z_{\mathrm{L}}+\frac{f \mathrm{~V}^{2}}{2 \mathrm{Dg}}(\mathrm{L}-x)+\frac{\mathrm{V}^{2}}{2 \mathrm{~g}}\left(\beta_{\mathrm{L}}-\beta(x)\right),
$$

where the hydraulic head

$$
H(x)=\frac{p(x)-p_{A}}{\rho g}+z(x) .
$$

Without loss of generality, we take $p_{A}=0$ and $p(x)$ to be the pressure in excess of $p_{A}$. Plotting $H(x)$ against $x$, as given by (4), yields the hydraulic grade line (HGL) for the pipeline under normal operating conditions. 


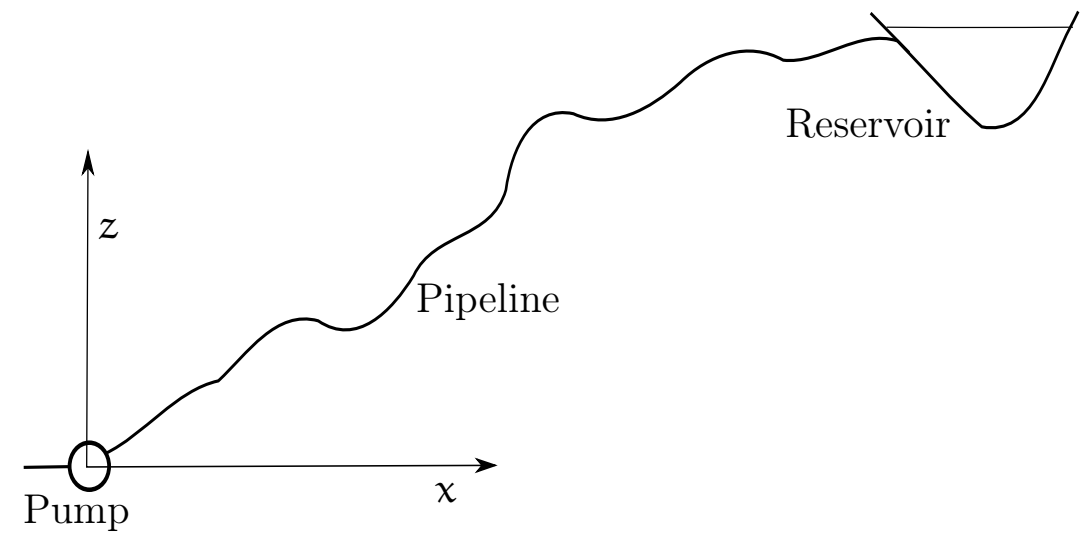

Figure 1: Schematic diagram of a pipeline from pump to reservoir, showing the coordinate system.

In the pipeline design process, the hydraulic head is of major importance. From (5) we see that if $\mathrm{H}(\mathrm{x})<z(\mathrm{x})$, that is, the hydraulic head drops below the value of the ground elevation at a position $x$ along the pipe, for example due to a pressure surge caused by a trip event, then the pressure in the pipe at that position becomes sub-atmospheric $\left(p(x)<p_{A}\right)$, or "negative" (taking $p_{A}=0$ ), with negative consequences for the smooth operation of the pipeline, including the possibility in extreme cases of catastrophic pipe collapse. Pipeline design involves prediction of the minimum hydraulic head envelope along the length of the pipeline under the most extreme anticipated operating conditions, and prevention of sub-atmospheric pipe pressure by choice of suitably sized pumps and pipes, and inclusion of surge protection devices (surge tanks, air cushion standpipes, etc.) at appropriate locations while, at the same time, minimising the cost of the system. Here we focus on the preliminary design done by SunWater for quotation purposes; the design must be sufficiently good that SunWater do not under-quote the pipeline or price themselves out of the market. Subsequently, if the quotation is accepted, then the package WATHAM is used by SunWater for a detailed analysis of 
pumps, pipes and surge mitigation devices for a given topography. This computer package is not used at the initial design phase because of the time taken both to set up the model and for each simulation.

The cost of pumping is mitigated by reducing the pump size and, therefore, the head at the source, $\mathrm{H}(0)$, but this will incur greater costs due to the need for such things as a significantly larger pipe for a given volume flux, a reduction in the volume flux and longer pumping times, additional pumping stations, and more downstream surge protection.

Figure 2 shows an example of the kind of information that is used at the initial design phase for sizing of pumps and pipes and to place appropriate surge protection. In constructing this figure we assume that $\beta(x)=0$ (no bends, joins, etc.). The HGL is shown under normal operating conditions; intersection of the HGL with the ground elevation indicates the need for a significant modification of the pipeline design, such as another pumping station or a bigger source pump to preclude subatmospheric pressure in the pipe under normal operating conditions. The curve labelled "Surgeline" is an estimate of the minimum hydraulic head due to the pressure surge following the worst-case scenario of the sudden loss of all pumps, that is, a complete pump-trip event, with associated check-valve closure. Intersection of this curve with the ground signals possible catastrophic pipe failure due to subatmospheric pressure and, therefore, the need for some kind of surge protection. Although a pipe in practice withstands some negative pressure, at the preliminary design phase any negative pressure is taken as an indicator of the need for surge protection.

A good estimate of the surgeline is critical to obtaining a good preliminary pipeline design with necessary, but not overly excessive, surge protection. A critical aspect of obtaining the surgeline is determining the initial change in head, $\Delta \mathrm{H}_{\mathrm{J}}<0$, at the pump(s) when they fail suddenly. This was the key quantity that the study group was asked to consider. It is normally calculated using the Joukowski formula, which relates a velocity change to a pressure change as discussed in Section 3, and assuming that the flow speed at the 
$\operatorname{pump}(\mathrm{s})$ drops to zero almost instantaneously. Thorley $[8, \S 1.2 .2, \S 1.2 .5]$ pointed out that in many systems this is the principal component of the total head change but that over time, and particularly on long pipelines, friction adds to the change in head. As also described by Thorley [8, §1.2.2, §2.2.1], this Joukowski head change at the pump(s) usually occurs over a nonzero period of time $\Delta t$ (typically 1-10 seconds), so that a pressure front/pulse develops that travels rapidly downstream with a speed a that depends on the properties of the pipe. The spatial length of this pressure pulse is $\ell=\mathrm{a} \Delta \mathrm{t}$; as it passes through a point $x$ downstream of the pump there is a pressure drop similar to that seen at the pump(s), although this happens over a later time period, $x / a \leqslant t \leqslant x / a+\Delta t$. After the initial pulse, the pressure continues to drop much more slowly due to friction. On reaching the end of the pipeline $x=\mathrm{L}$ where the pressure is atmospheric, the pressure pulse will be reflected back along the pipeline with opposite sign so that in a section of pipe of length $\ell / 2$ (half the length of the pressure pulse), at the very end of the pipeline, the hydraulic head does not fall by the full Joukowski head change $\Delta \mathrm{H}_{\mathrm{J}}$. As the reflected pulse travels further towards the pump(s) it causes an increase in the pressure. Thus, as shown in Figure 2 the surgeline, or minimum hydraulic head envelope, is depicted as a curve from the HGL at $x=\mathrm{L}$, through the point $\left(\mathrm{L}-\ell / 2, \mathrm{H}(\mathrm{L}-\ell / 2)+\Delta \mathrm{H}_{\mathrm{J}}\right)$, to the minimum hydraulic head $\mathrm{H}_{\min }$, and then extends horizontally back to $x=0$. The minimum hydraulic head $\mathrm{H}_{\min }=\mathrm{H}(0)+\Delta \mathrm{H}_{\mathrm{J}}+\Delta \mathrm{H}_{\mathrm{F}}$, where $\Delta \mathrm{H}_{\mathrm{F}}<0$ is the frictional head drop at the pump(s). Thorley [8] describes the construction of the surgeline.

The example surgelines supplied by SunWater to the group did not correspond to the description given above. Instead of a constant head over most of the length of the pipe, one of the curves indicated the Joukowski head drop, that is, $\mathrm{H}_{\min }(\mathrm{x})=\mathrm{H}(\mathrm{x})+\Delta \mathrm{H}_{\mathrm{J}}$ (where $\Delta \mathrm{H}_{\mathrm{J}}<0$ ), along the length of the pipe until reflection of the pressure wave resulted in the surgeline curving up to the HGL at $x=\mathrm{L}$. Another curve in the SunWater presentation showed the surgeline curving upwards immediately after the pump, without any horizontal section. However, no further details were given for this latter case. An instructional 
document prepared by the large German water industry company KSB [4], also shows the surgeline as sloping upwards towards the HGL immediately after the pump. This surgeline was based on measured data from a pipeline installation following a pump trip, although again few details are given [4, Figure 2.1-b]. There would, therefore, seem to be no universal consensus on the form that the surgeline takes, or its dependence on specific pipeline and operational parameters. Thorley $[8, \S 1.2 .4]$ describes a 'rapid' event where the pipeline is sufficiently short that the pressure pulse travels to the reservoir and back to the pump in a time less than the time $\Delta t$ over which the pressure at the pump(s) falls by the Joukowski head change. In this situation the surgeline would be a monotonic increasing curve from $x=0$ to $x=L$ as in the last two examples.

The two simple cases in Figure 2 show one in which the pump head is not sufficient to prevent the need for surge protection on the first hill. The associated surgeline shows that some form of surge protection would be required on both high points. The second case (right-hand panel) has a larger initial hydraulic head and a surgeline that indicates that surge protection is not needed until the second peak. Using such a simple tool, a pipeline, including pipe sizes, pump sizes and locations and size and position of surge protection, can be designed and optimised to minimize cost. However, because of the interdependence of the pipe diameter and material, flow speed, friction factor, required head and hence pump size, it is not a simple task to obtain a suitable design.

\section{Head loss at the pump: the Joukowski formula}

The first step in predicting a surgeline is to determine the change in the hydraulic head at the pump immediately after a trip event. This is found by Newton's 2nd law to depend on the change in the velocity $\Delta \mathrm{V}$, and the 
Figure 2: Diagram showing an example of pipeline design over $175 \mathrm{~km}$ with an elevation increase of $84 \mathrm{~m}$ and a flux of about $0.7 \mathrm{~m}^{3} / \mathrm{s}$. For the given topography ("Ground") two different hydraulic grade lines ("HGL") are shown with their respective minimum hydraulic head envelopes (dashed "Surgeline"). In the top figure $(\mathrm{V}=0.36 \mathrm{~m} / \mathrm{s}, \mathrm{H}(0)=$ $99.5 \mathrm{~m}, \mathrm{D}=1.58 \mathrm{~m})$, insufficient hydraulic head is provided by the pump to prevent surge protection at the first hill. In the lower figure $(\mathrm{V}=0.55 \mathrm{~m} / \mathrm{s}, \mathrm{H}(0)=$ $129.7 \mathrm{~m}, \mathrm{D}=1.27 \mathrm{~m})$ an increase in pump power, and therefore hydraulic head at the pump, means that surge protection would not be required until the second peak.
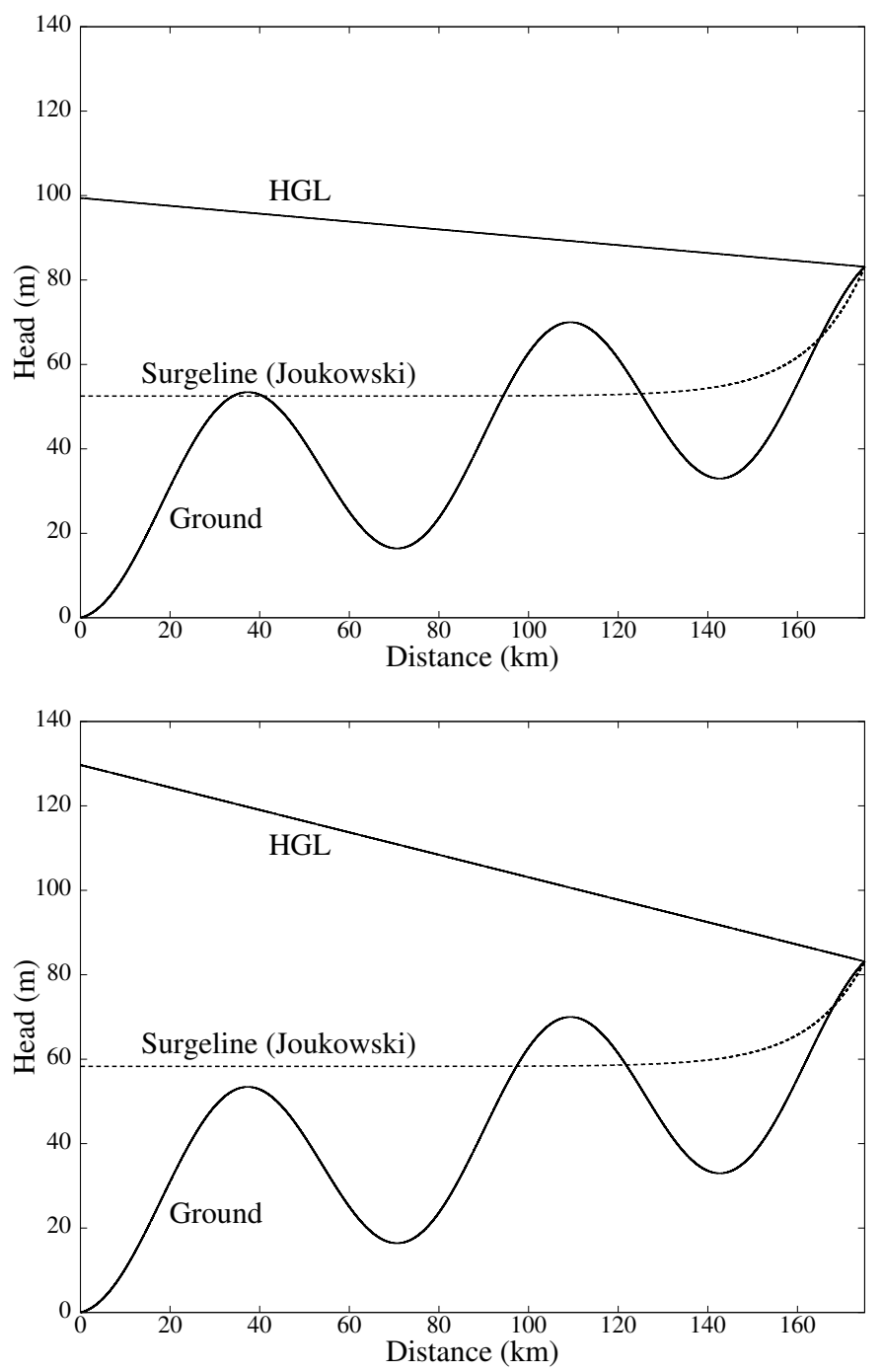
propagation speed of the pulse a, also called the celerity, as encapsulated in the Joukowski formula,

$$
\Delta \mathrm{H}=\frac{\mathrm{a}}{\mathrm{g}} \Delta \mathrm{V} .
$$

A straightforward derivation of this formula is given by Chaudhry [1, §1.4], which is not repeated here. The MISG group checked this derivation and found it to be correct. Note that $\Delta \mathrm{V}<0$ is a drop in the flow speed which will result in a drop in the hydraulic head, $\Delta \mathrm{H}<0$.

Chaudhry [1] also shows that, for a slightly compressible fluid in a rigid pipe, the propagation speed $a=\sqrt{K / \rho}$ where $\rho$ is the (initial) fluid density and $\mathrm{K}=\rho \mathrm{dp} / \mathrm{d} \rho$ is the bulk modulus of elasticity of the fluid. The large value of $\mathrm{K}$ for water (around 2.2 GPa) justifies the incompressible approximation in most flow situations. However, in some transient flow situations such as in long pipelines, compressibility has a significant effect, since a pressure disturbance may take appreciable time to transit the length of the pipe. The "effective compressibility" of the pipe-fluid system has contributions not only from the actual compressibility of the water, but also from the elastic response of the pipe itself, which will expand or contract radially in response to pressure disturbances. The pipe elasticity will increase the effective compressibility over that of the fluid alone, that is, decrease the effective bulk modulus of elasticity compared to that of the fluid. A modified formula for the wave speed a for thin-walled elastic conduits is [1]

$$
a=\sqrt{\frac{K}{\rho}\left(\frac{1}{1+(K / E)(D / s) c}\right)},
$$

where $E$ is the Young's modulus of the pipe material, $D$ is the internal pipe diameter, $s$ is the thickness of the pipe wall, and $\mathrm{c}$ is a dimensionless quantity that takes different values depending on the extent to which the pipe is able to expand axially. If there is no constraint on local axial expansion of the pipe, such as would be the case if there are frequent axial expansion joints, then $c=1$. If the pipe is rigidly restrained in the axial direction, then $c=1-v^{2}$ where $v$ is Poisson's ratio. Intermediate degrees of axial 
constraint correspond to values of $\mathrm{c}$ between these limits. This formula for $\mathrm{a}$ is simply the propagation speed in a rigid pipe multiplied by a correction factor for pipe elasticity. Since the correction factor will always be less than one, the wave propagation speed is reduced compared to that in a rigid pipe. There can be considerable variation in this correction factor between different pipe materials whose Young's moduli may vary between $200 \mathrm{GPa}$ for cement lined steel pipes and $1 \mathrm{GPa}$ for plastic HDPE pipes. The bulk modulus of elasticity of water, $\mathrm{K}$, is significantly reduced by the presence of small bubbles and dissolved air. Typically for steel pipes, $a$ is of the order of $1000 \mathrm{~m} / \mathrm{s}$, which is to be compared to the speed of sound in water in a rigid pipe of around $1500 \mathrm{~m} / \mathrm{s}$.

The initial drop in flow speed at the pump, which gives the change in hydraulic head via (6), depends on whether a check valve is used to prevent back flow. Since SunWater advised that a check valve is always used for protection of the $\operatorname{pump}(\mathrm{s})$, it was assumed that, to a good approximation, the water is brought to an instantaneous stop by the valve, which is also the worst case scenario.

As an example, consider a steady state flow with speed $V_{0}$ in the direction of increasing $x$, and let the head at some point $P$ in the pipe be $H_{P}$. If the flow at $P$ is suddenly stopped, then there will be an instantaneous jump in head at $\mathrm{P}$ of

$$
\Delta \mathrm{H}=\frac{\mathrm{a}}{\mathrm{g}} \Delta \mathrm{V}=\frac{\mathrm{a}}{\mathrm{g}}\left(0-\mathrm{V}_{0}\right)=-\frac{\mathrm{a}}{\mathrm{g}} \mathrm{V}_{0} ;
$$

that is, there is a decrease in the hydraulic head of magnitude $a V_{0} / g$. Conversely, there will be a rise in head of the same magnitude at $P$ if the initial steady-state flow velocity is $V_{0}<0$, that is in the direction of decreasing $x$.

With the wave speed computed from (7) and the change in hydraulic head at the pump due to a trip event computed by the Joukowski formula, it is a simple exercise to draw the surgeline neglecting any frictional component. 


\section{The water hammer equations}

The propagation of the pulse along the pipeline following a trip event, is more accurately described by a set of partial differential equations, known as the water hammer equations, much like those for sound propagation. These were solved to obtain the surgeline more accurately for comparison with that determined by a preliminary pipeline design as described in Section 2. These equations are nonlinear, which means that they cannot be solved exactly. However, they can be solved quite accurately on a computer. The component of WATHAM that resolves the pressures in the pipe solves these equations.

The equations describing transient flow in the pipe are

$$
\begin{aligned}
& g \frac{\partial H}{\partial x}+\frac{f}{2 D} V|V|+V \frac{\partial V}{\partial x}+\frac{\partial V}{\partial t}=0 \\
& \frac{a^{2}}{g} \frac{\partial V}{\partial x}+V \frac{\partial H}{\partial x}+\frac{\partial H}{\partial t}=0
\end{aligned}
$$

where $H(x, t)$ and $V(x, t)$ are the hydraulic head and flow speed averaged over the cross section of the pipe at position $x$ along the pipe at time $t$; writing $\mathrm{V}|\mathrm{V}|$ instead of $\mathrm{V}^{2}$ in (8) allows for reverse flow. As before, $\mathrm{D}$ is the diameter of the pipe, assumed to be constant, $a$ is the celerity or speed of propagation of a pressure disturbance in the pipe-fluid system (Section 3), and $\boldsymbol{f}$ is the friction factor which will be discussed next. Equations (8) and (9) represent the conservation of momentum in the axial direction and of fluid mass, respectively. Two key assumptions implicit in these one-dimensional equations are:

- any curvature in the pipeline, in either the horizontal or vertical planes, is small relative to the inverse diameter of the pipe, which justifies using the distance $x$ as a valid one-dimensional axial coordinate in the equations; and

- the flow in the pipe is turbulent and reasonably approximates "plug flow" with near uniform velocity, density and pressure profiles across 
each cross section, so that use of cross-section-averaged quantities in the equations is justified.

Equations (8) and (9) may be further simplified because the flow speed $\mathrm{V}$ is much less than the wave propagation speed $\mathrm{a}$; that is, $\mathrm{V} / \mathrm{a} \ll 1$. A nondimensionalisation, using length scale $\mathrm{L}$, fluid velocity scale $\mathcal{V} \ll a$ and time scale $\mathrm{L} / \mathrm{a}$, shows that the nonlinear convective terms $\mathrm{V} \partial \mathrm{V} / \partial \mathrm{x}$ and $\mathrm{V} \partial \mathrm{H} / \partial \mathrm{x}$ are small relative to the other terms, justifying their neglect. This is a very typical simplification of the water hammer equations [e.g. 1].

We come now to a discussion of the friction factor $f$ appearing in (8). This arises from the Darcy-Weisbach expression for the head loss in a pipe under steady state conditions,

$$
\frac{\Delta \mathrm{H}}{\Delta \mathrm{x}}=-\mathrm{f} \frac{\mathrm{V}^{2}}{2 \mathrm{gD}}
$$

which, incidentally, may be determined from (8) if we set $\partial \mathrm{V} / \partial \mathrm{t}=0$ (steady flow) and $\partial \mathrm{V} / \partial \mathrm{x}=0$ (incompressible flow), or by taking the $\mathrm{x}$-derivative of the Bernoulli equation (4). The value of the friction factor $\boldsymbol{f}$ is obtained by semi-empirical means, usually by reference to the Moody diagram [6], or other related analytical expressions such as the implicit Colebrook equation or the explicit formula of Swamee \& Jain [7]. Although the friction factor is non-dimensional, it is not necessarily constant for any given pipe. From dimensional considerations, we expect that

$$
f=f(R e, \epsilon / D),
$$

where $\operatorname{Re}=V D \rho / \mu$ is the Reynolds number of the flow for a fluid with viscosity $\mu$, and $\epsilon$ is a roughness parameter characterising the size of the roughness protrusions on the wall of the pipe. A feature of the Moody diagram is that for a pipe of roughness $\epsilon / D$ there is a value of Re above which the flow is "completely turbulent" and $f$ is, essentially, independent of Re. However below this Reynolds number $f$ depends on both Re and $\epsilon / D$, so that the head loss in (10) will not be quadratic in V. Typically, the head loss behaves with a lower exponent of $\mathrm{V}$ than two, and for laminar flow, is linear in $\mathrm{V}$. 
Strictly speaking, the friction factor is defined and determined under steady flow conditions, so its use in (8) assumes that this steady state value is also reasonable under transient flow conditions. In reality, it takes a finite time for steady state conditions to be established, so the use of steady state values in unsteady flows does not strictly follow, although invariably in practical calculations, the steady state value is used.

\section{Solution of the simplified water hammer equations}

\subsection{The method of characteristics}

Our task is now to solve the simplified water hammer equations

$$
\begin{aligned}
& g \frac{\partial H}{\partial x}+\frac{f}{2 D} V|V|+\frac{\partial V}{\partial t}=0, \\
& \frac{a^{2}}{g} \frac{\partial V}{\partial x}+\frac{\partial H}{\partial t}=0
\end{aligned}
$$

subject to initial conditions $\mathrm{H}(x, 0)$ given by $(4)$ and $\mathrm{V}(x, 0)$ the specified constant steady state velocity, with boundary conditions $V(0, t)=0$ and $H(L, t)=z_{L}$ (where we have set $p_{A}=0$ ). For this we use the method of characteristics, and so introduce the new variables

$$
\xi=x-a t, \quad \eta=x+a t .
$$

Transforming the derivatives in (11) and (12) to derivatives with respect to $\xi$ and $\eta$, we obtain after some manipulation

$$
\begin{aligned}
& \frac{\partial H}{\partial \xi}-\frac{a}{g} \frac{\partial V}{\partial \xi}+\frac{f}{4 g D} V|V|=0 \\
& \frac{\partial H}{\partial \eta}+\frac{a}{g} \frac{\partial V}{\partial \eta}+\frac{f}{4 g D} V|V|=0
\end{aligned}
$$


Figure 3 shows the orientation of the lines of constant $\xi$ and constant $\eta$ in the $x$-t plane. Now integrating (13) along a line of constant $\eta$ and (14) along a line of constant $\xi$ leads to

$$
\begin{aligned}
& \left.\left(\mathrm{H}-\frac{\mathrm{a}}{\mathrm{g}} \mathrm{V}\right)\right|_{\xi_{0}} ^{\xi_{1}}=-\int_{\xi_{0}}^{\xi_{1}} \frac{\mathrm{f}}{4 \mathrm{gD}} \mathrm{V}|\mathrm{V}| \mathrm{d} \xi \quad(\eta=\text { constant }), \\
& \left.\left(\mathrm{H}+\frac{\mathrm{a}}{\mathrm{g}} \mathrm{V}\right)\right|_{\eta_{0}} ^{\eta_{1}}=-\int_{\eta_{0}}^{\eta_{1}} \frac{\mathrm{f}}{4 \mathrm{gD}} \mathrm{V}|\mathrm{V}| \mathrm{d} \eta \quad(\xi=\text { constant }),
\end{aligned}
$$

and returning to the original variables $x$ and $t$ gives

$$
\begin{aligned}
& \left.\left(H-\frac{a}{g} V\right)\right|_{x_{0}} ^{x_{1}}=-\int_{x_{0}}^{x_{1}} \frac{f}{2 g D} V|V| d x \quad(x+a t=\text { constant }), \\
& \left.\left(H+\frac{a}{g} V\right)\right|_{x_{0}} ^{x_{1}}=-\int_{x_{0}}^{x_{1}} \frac{f}{2 g D} V|V| d x \quad(x-a t=\text { constant }) .
\end{aligned}
$$

These equations are the basis of the numerical solution described in Subsection 5.3.

\subsection{An alternative derivation of Joukowski's formula}

It is of interest to first use (17) and (18) to derive Joukowski's formula for the instantaneous response to a change of conditions. With reference to Figure 4, consider the characteristic $\eta=$ constant joining points $P^{\prime}$ and $P^{\prime \prime}$ in the $\mathrm{x}$-t plane. Let $\mathrm{P}^{\prime} \rightarrow \mathrm{P}$, then $\mathrm{P}^{\prime \prime}$ also approaches $\mathrm{P}$, and the distance $\mathrm{P}^{\prime} \mathrm{P}^{\prime \prime}$ approaches 0 . Thus, in the limit, from (17)

$$
\lim _{P^{\prime \prime} \rightarrow P}\left(H-\frac{a}{g} V\right)=\lim _{P^{\prime} \rightarrow P}\left(H-\frac{a}{g} V\right) .
$$

Writing

$$
\Delta H=\lim _{P^{\prime \prime} \rightarrow P} H-\lim _{P^{\prime} \rightarrow P} H \text { and } \Delta V=\lim _{P^{\prime \prime} \rightarrow P} V-\lim _{P^{\prime} \rightarrow P} V,
$$


Figure 3: The orientation of the characteristics $\xi=$ constant and $\eta=$ constant in the $x$ - $t$ plane.

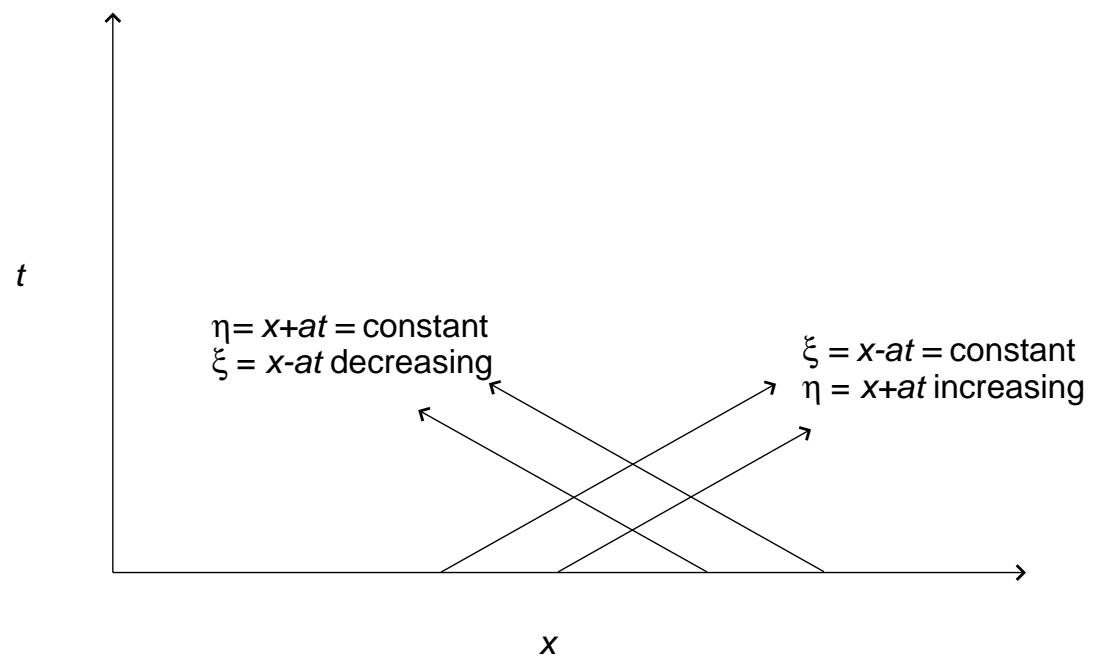

we obtain Joukowski's relation

$$
\Delta \mathrm{H}=\frac{\mathrm{a}}{\mathrm{g}} \Delta \mathrm{V} .
$$

If $\mathrm{H}$ and $\mathrm{V}$ are continuous in the neighbourhood of $\mathrm{P}$, then both sides of this equation are zero and the relationship is trivial. However, if there are discontinuous changes in $\mathrm{H}$ and $\mathrm{V}$, then (19) shows how these must be related.

Joukowski's relation is completely general, and applies to any sudden change in the pipeline conditions. However, it only gives the instantaneous local response. As discussed in Section 6, the longer term response, and the response some distance from the change, are quite different due to frictional transmission effects. 
Figure 4: Derivation of Joukowski's relation for an instantaneous change in conditions in the neighbourhood of $\mathrm{P}$.

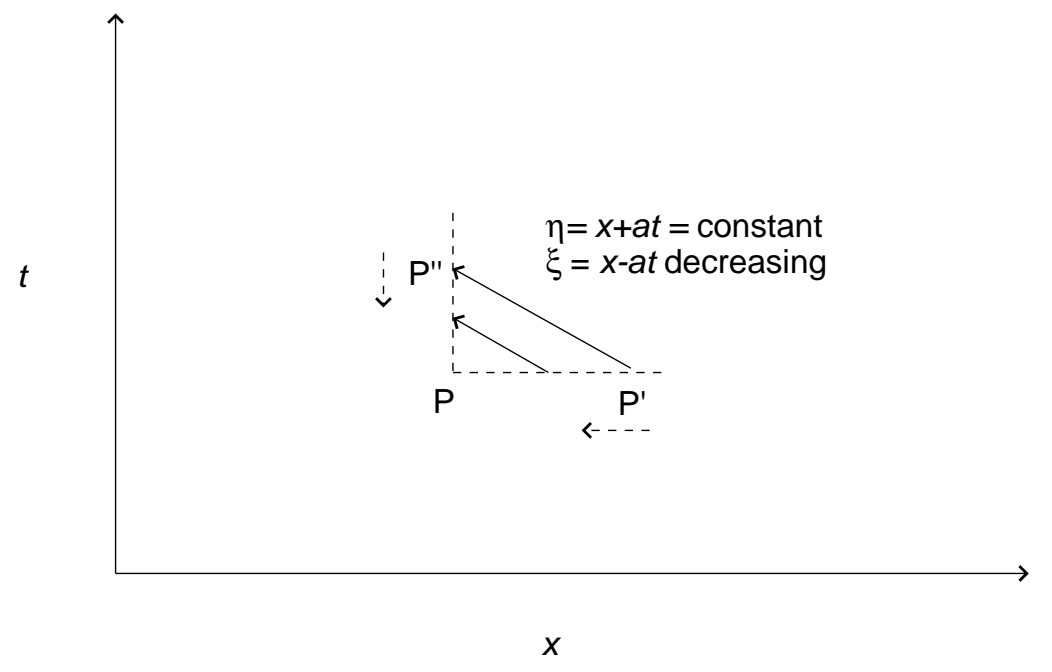

\subsection{Numerical solution}

We use (17) and (18) as the basis for solving the water hammer equations. In Figure 5 we discretise the $x$ and $t$ dimensions using grid spacings of $\Delta x$ and $\Delta \mathrm{t}$ respectively. These grid spacings are related by $\Delta \mathrm{x}=\mathrm{a} \Delta \mathrm{t}$, and so grid points at successive time levels are connected by the characteristics lines, as illustrated in Figure 5. Now, suppose we have approximate values for $\mathrm{H}$ and $\mathrm{V}$ at points $\mathrm{P}_{-}$and $\mathrm{P}_{+}$at some time. We then advance the solution by a time step $\Delta t$ to the point $\mathrm{P}^{\prime}$ by using (17) along the characteristic line $\mathrm{P}_{+} \mathrm{P}^{\prime}$, and (18) along the characteristic line $\mathrm{P}_{-} \mathrm{P}^{\prime}$. In using (17) and (18), the friction integrals on the right hand sides are approximated by supposing the velocity is constant throughout each interval of integration and using the 
Figure 5: The basis of the explicit time stepping scheme for numerically solving (17) and (18). The spatial discretisation parameter $\Delta x$ and the time step $\Delta \mathrm{t}$ are related by $\Delta \mathrm{x}=\mathrm{a} \Delta \mathrm{t}$.

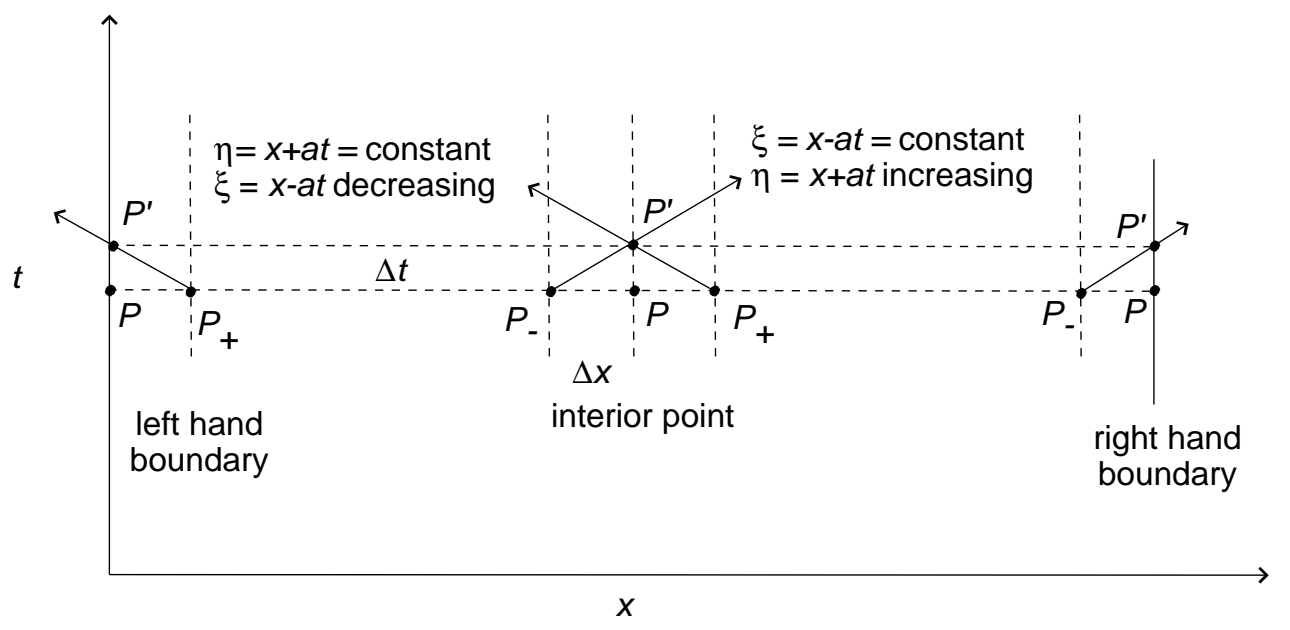

known velocities at the points $\mathrm{P}_{+}$and $\mathrm{P}_{-}$, respectively:

$$
\begin{aligned}
& \left.\left(\mathrm{H}-\frac{\mathrm{a}}{\mathrm{g}} \mathrm{V}\right)\right|_{\mathrm{P}_{+}} ^{\mathrm{P}^{\prime}} \approx \frac{\mathrm{f} \Delta \mathrm{x}}{2 \mathrm{gD}} \mathrm{V}\left(\mathrm{P}_{+}\right)\left|\mathrm{V}\left(\mathrm{P}_{+}\right)\right| ; \\
& \left.\left(\mathrm{H}+\frac{\mathrm{a}}{\mathrm{g}} \mathrm{V}\right)\right|_{\mathrm{P}_{-}} ^{\mathrm{P}^{\prime}} \approx-\frac{\mathrm{f} \Delta \mathrm{x}}{2 \mathrm{gD}} \mathrm{V}\left(\mathrm{P}_{-}\right)\left|\mathrm{V}\left(\mathrm{P}_{-}\right)\right|
\end{aligned}
$$

In (17), $\mathrm{x}$ is decreasing along the characteristic line $\mathrm{P}_{+} \mathrm{P}^{\prime}$, and so there is an implied negative sign in the evaluation of the integral on the right hand side, which leads to a positive sign in the right hand side of the first equation above. In this way, we obtain values for

$$
\mathrm{H}-\frac{\mathrm{a}}{\mathrm{g}} \mathrm{V} \text { and } \mathrm{H}+\frac{\mathrm{a}}{\mathrm{g}} \mathrm{V}
$$

at the new point $\mathrm{P}^{\prime}$. Solving this non-singular $2 \times 2$ linear system, gives us values for $\mathrm{H}$ and $\mathrm{V}$ at $\mathrm{P}^{\prime}$. 
The above description relates to interior points along the pipeline. The situation is usually slightly simpler at the endpoints of the pipeline, as there are specified boundary conditions at these points. These boundary conditions provide a relationship involving $\mathrm{H}$ and $\mathrm{V}$ at each of the boundary points. As an example, suppose there is a specified head boundary condition $\mathrm{H}=\mathrm{H}_{\mathrm{L}}$ at the right hand boundary in Figure 5. We use (18) to advance the solution from $\mathrm{P}_{-}$to $\mathrm{P}^{\prime}$ along the characteristic which gives us the value of $\mathrm{H}+(\mathrm{a} / \mathrm{g}) \mathrm{V}$ at $\mathrm{P}^{\prime}$. Since we know $\mathrm{H}$ at $\mathrm{P}^{\prime}$ from the boundary condition, we are able to determine $\mathrm{V}$. In the same way, if the boundary condition is a specified velocity, $\mathrm{V}=\mathrm{V}_{\mathrm{L}}$, then $\mathrm{H}$ is determined. More generally, a boundary condition involving some relationship between $\mathrm{H}$ and $\mathrm{V}$, such as might arise from the operating curves of a valve, pump or other fitting, is solved simultaneously with this advanced value of $\mathrm{H}+(\mathrm{a} / \mathrm{g}) \mathrm{V}$ at $\mathrm{P}^{\prime}$, to again obtain values for both $\mathrm{H}$ and $V$ at $P^{\prime}$. An analogous situation applies at a left hand boundary point, except that (17) is used to advance the solution for $\mathrm{H}-(\mathrm{a} / \mathrm{g}) \mathrm{V}$ along $\mathrm{P}_{+} \mathrm{P}^{\prime}$, as depicted in Figure 5.

Returning to the approximation used in the evaluation of the friction integrals, an alternative, and presumably more accurate approach would be to use a trapezoidal rule approximation. In the notation of Figure 5, this would become for an interior point $\mathrm{P}^{\prime}$

$$
\begin{aligned}
& \left.\left(\mathrm{H}-\frac{\mathrm{a}}{\mathrm{g}} \mathrm{V}\right)\right|_{\mathrm{P}_{+}} ^{\mathrm{P}^{\prime}} \approx \frac{\mathrm{f} \Delta \mathrm{x}}{4 \mathrm{gD}}\left[\mathrm{V}\left(\mathrm{P}^{\prime}\right)\left|\mathrm{V}\left(\mathrm{P}^{\prime}\right)\right|+\mathrm{V}\left(\mathrm{P}_{+}\right)\left|\mathrm{V}\left(\mathrm{P}_{+}\right)\right|\right] \\
& \left.\left(\mathrm{H}+\frac{\mathrm{a}}{\mathrm{g}} \mathrm{V}\right)\right|_{\mathrm{P}_{-}} ^{\mathrm{P}^{\prime}} \approx-\frac{\mathrm{f} \Delta \mathrm{x}}{4 \mathrm{gD}}\left[\mathrm{V}\left(\mathrm{P}^{\prime}\right)\left|\mathrm{V}\left(\mathrm{P}^{\prime}\right)\right|+\mathrm{V}\left(\mathrm{P}_{-}\right)\left|\mathrm{V}\left(\mathrm{P}_{-}\right)\right|\right]
\end{aligned}
$$

This is a nonlinear system of equations for the unknowns $\mathrm{V}\left(\mathrm{P}^{\prime}\right)$ and $\mathrm{H}\left(\mathrm{P}^{\prime}\right)$. (It is quadratic, although we do not make explicit use of this.) As $f$ and $V$ are usually small, the system is readily solved by a simple iteration that uses the most recent iterate for $\mathrm{V}\left(\mathrm{P}^{\prime}\right)$ in the trapezoidal rule expression on the right hand side, and then solves the left hand side $2 \times 2$ linear system for updated values of $\mathrm{V}\left(\mathrm{P}^{\prime}\right)$ and $\mathrm{H}\left(\mathrm{P}^{\prime}\right)$. This process is repeated until sufficient accuracy is 
achieved. The iteration is started by using, as the initial iterate, the solution described earlier which took the velocity to be constant throughout each interval of integration using the known velocities at the points $\mathrm{P}_{+}$and $\mathrm{P}_{-}$ respectively. A similar approach is taken with the friction integrals appearing in the boundary conditions.

Our experience in running a number of examples, such as those described next in Section 6, is that the use of this trapezoidal rule approximation has only a negligible effect on the solution. Therefore, for most practical purposes, the simpler constant-velocity approximation and the resulting equations (20) and (21) should be sufficient.

\section{Simple examples of pump trip events}

\subsection{A long pipeline example}

To try to understand the transients associated with a pump trip event, consider the simple case illustrated in Figure 6. This shows the steady state hydraulic grade line of a pipeline connecting two reservoirs. Water is transported from the higher reservoir to the lower reservoir over a distance of $200 \mathrm{~km}$. Midway between the two reservoirs at $x=0$ there is a pump that provides additional head to overcome the frictional losses in the pipeline. In reality, there may well be additional pumping locations and a number of surge protection units in the pipeline; however, for the purposes of seeking to intuitively understand the response to a pump trip event, we restrict ourselves to this simplified layout.

The various hydraulic parameters used are shown in Figure 6. The friction factor is based on the Moody diagram for a cast iron pipe with roughness $\epsilon=0.25 \mathrm{~mm}$. This places the flow conditions in the transition zone between the smooth pipe limit (where $f=f(R e)$ only) and the rough pipe (complete turbulence) limit (where $f=f(\epsilon / D)$ only). For velocities in the range 0.1- 
Figure 6: The hydraulic grade line of a simple pipe system in steady state connecting two reservoirs with an intermediate pump. The flow rate is $1 \mathrm{~ms}^{-1}$ and the pump boosts the head by $\Delta \mathrm{H}=200 \mathrm{~m}$. The hydraulic parameters used in the model are shown.

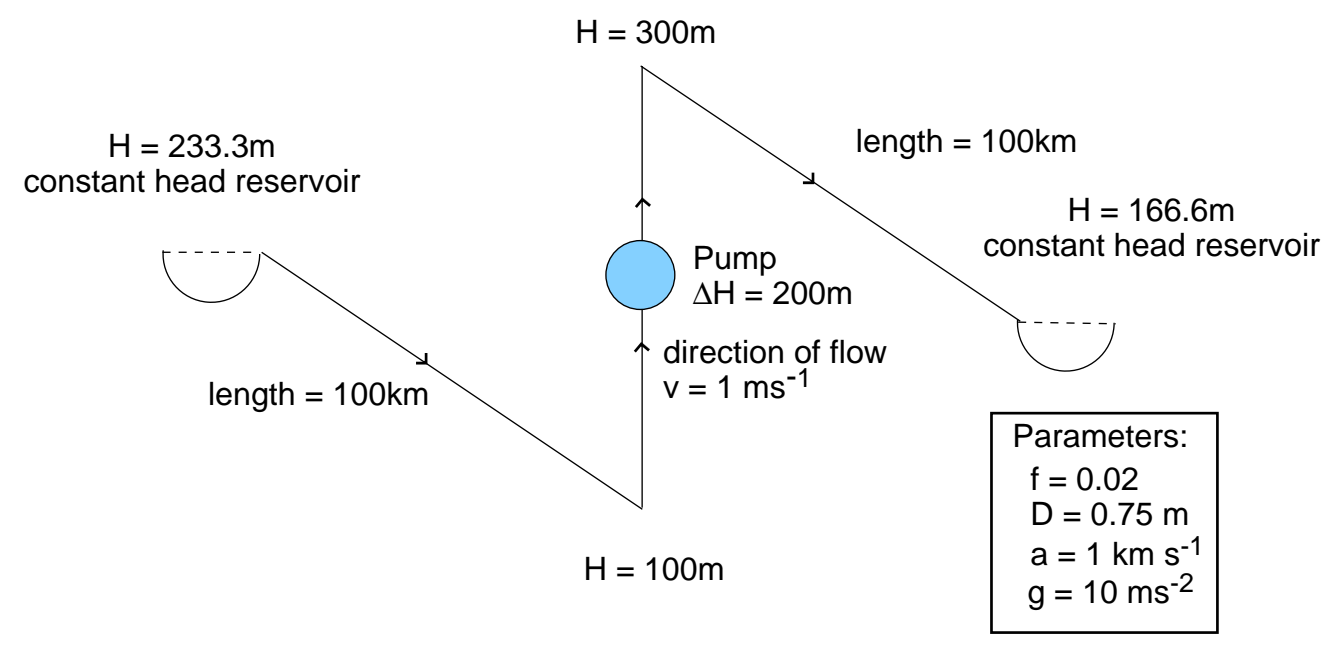

$1.0 \mathrm{~ms}^{-1}$, the Moody diagram gives $\mathrm{f} \approx 0.022-0.017$. We therefore take the constant value $f=0.02$ over this entire velocity range.

Figure 6 notes the values for the steady state solution of this situation. We now imagine that at time $t=0$ the pump at $x=0$ trips (shuts down suddenly), the check valve (instantaneously) closes, and flow immediately ceases just upstream and downstream of the pump, that is, at $x=0^{-}$and $x=0^{+}$. This isolates the upstream and downstream flows, which now evolve independently. In the transient flows that take place, we assume that $\mathrm{V}=0$ at $x=0$, and $H$ remains constant at each of the reservoir ends of the pipeline. The transient behaviour in the pipeline has been simulated for $200 \mathrm{~s}$, which corresponds to the time for the pressure pulses to travel the $200 \mathrm{~km}$ to the reservoirs and back again to the pump at a speed of $1000 \mathrm{~m} / \mathrm{s}$.

We first consider the downstream side of the pump. Figure 7 shows the time 
evolution of $\mathrm{H}$ and $\mathrm{V}$ at the pump and at locations $5 \mathrm{~km}, 50 \mathrm{~km}$ and $100 \mathrm{~km}$ downstream for times from 0 to $200 \mathrm{~s}$. (Recall that the lower reservoir is $100 \mathrm{~km}$ downstream.) Figures 8 and 9 show $\mathrm{H}$ and $\mathrm{V}$ along the entire downstream portion of the pipeline at the selected times of 0, 5, 50, 100, 105, 150 and $200 \mathrm{~s}$ after tripping. Figures 8 and 9 also depict a simple linear ground elevation topography from $z(0)=100 \mathrm{~m}$ to $z(\mathrm{~L})=166.6 \mathrm{~m}$, which is used in our discussion at the end of this subsection.

The $x=0 \mathrm{~km}$ plot shows that the head on the downstream side of the pump suddenly falls by $100 \mathrm{~m}$ just after the trip at $\mathrm{t}=0$. This is consistent with the Joukowski equation, as we would expect, corresponding to a sudden change of velocity of $-1 \mathrm{~ms}^{-1}$ as flow at the pump ceases. However, after this initial sharp drop, the head continues to fall in an almost linear fashion with time for the remainder of the $200 \mathrm{~s}$ of the simulation. The reason for this is seen by looking at the other plots in Figure 7 . At the $5 \mathrm{~km}$ and $50 \mathrm{~km}$ locations the initial downstream travelling pulse is reduced in magnitude (the head drop successively reduces) and is insufficient to completely stop the flow. The original fluid velocity of $1 \mathrm{~ms}^{-1}$ is only reduced to about 0.03 and $0.3 \mathrm{~ms}^{-1}$ respectively at these locations because frictional effects are damping the magnitude of the pressure pulse. Thus, after this initial pressure pulse has passed a location, the fluid continues to move downstream with a reduced velocity, and this reduced velocity is greater the further down the pipe we go. Thus, any element of fluid is gradually drawing away from the fluid behind it, and so we expect some rarefaction or thinning of the fluid to occur, which results in a further falling of head behind the pulse as it travels towards the downstream reservoir.

From the plots in Figure 7, we see that at $t=100 \mathrm{~s}$, which is the time at which the initial pressure pulse reaches the downstream reservoir, the head at $0 \mathrm{~km}, 5 \mathrm{~km}$ and $50 \mathrm{~km}$ are all approximately equal at $135 \mathrm{~m}$. (This is also seen from the $t=100 \mathrm{~s}$ plot in Figure 8, which shows that the head is almost uniform behind the pulse.) This pressure head represents a further drop in head of $65 \mathrm{~m}$, on top of the initial Joukowski drop of $100 \mathrm{~m}$ at the pump. At $t=100 \mathrm{~s}$, the pulse reaches the downstream reservoir and there is some 
"reflection", depending upon the mismatch of head at the reservoir between the constant head terminus condition and the arriving pressure pulse. We look at this in the next paragraph. However, first note that it takes another $100 \mathrm{~s}$ before this "reflected" pulse reaches the pump. In the meantime, the head at the pump continues to fall. As shown in Figure 9 at 200 s, just as the reflected pulse reaches the pump, the head at the pump has already fallen to approximately $80 \mathrm{~m}$, which is $120 \mathrm{~m}$ below the initial Joukowski drop of $100 \mathrm{~m}$. We therefore see that, depending on the circumstances, the head drop at the pump can be significantly greater than that predicted by the instantaneous Joukowski result - in this case over double. Should the head fall below ground level, this may have potentially grave consequences such as severe mechanical damage to the pipe, and even pipe collapse.

The $t=100$ s plot in Figure 8 shows the situation as the downstream pulse arrives at the reservoir. The head in the pipe is substantially uniform, but it is below the constant head at the reservoir. This mismatch triggers an instantaneous change in velocity at the reservoir end of the pipe (again, incidentally, given by the Joukowski formula) and a reflected positive pressure pulse now traves upstream from the reservoir. As this pulse travels back towards the pump a reverse flow develops in the pipe. As the $t=200 \mathrm{~s}$ plot in Figure 9 shows, when this pulse reaches the pump, the flow conditions along the pipe approximate a uniform reverse hydraulic grade line with a uniform reverse flow. This reverse flow velocity is approximately $30 \%$ of the original flow velocity and the reverse hydraulic gradient is about $40 \%$ of its original value.

That the head in the pipe is below the head at the reservoir at $t=100 \mathrm{~s}$ can also have serious consequences upstream from the reservoir. Depending on the local topography, the water pressure in the pipe may well fall below atmospheric, or even approach a vacuum. Again, this is undesirable and may lead to serious pipe damage or collapse.

To make the discussion more concrete, consider the case of the simple ground elevation topography shown by the dashed lines in Figures 8 and 9, namely 
a constant upward sloping topography from the pump to the downstream reservoir. Here the pump is taken to be at an elevation of $100 \mathrm{~m}$. Figure 8 shows that at some time between $50 \mathrm{~s}$ and $100 \mathrm{~s}$ after the trip, the head curve falls beneath the elevation line. This first occurs somewhere near $x=75 \mathrm{~km}$ downstream from the pump. Once this happens, the pressure in the pipeline becomes negative. Recall that we are using gauge pressure, with atmospheric pressure being the reference pressure. Thus, the pressure at that point falls below atmospheric, which, as just mentioned, can have serious undesirable consequences. So for this simple example, the above analysis would suggest the need to introduce some surge protection near this point.

The actual numerical values presented here are obviously configuration specific; however, the overall principle is clear, namely that, due to frictional effects, there is a continuing head drop on the downstream side of the pump after the initial step change. This can be substantially greater than the instantaneous drop predicted by Joukowski, and this drop continues until the reflected pulse reaches the pump from the reservoir. The reflected pulse brings with it a reverse flow that tends to increase the head at the pump.

Now consider the upstream side of the pump. Figure 10 shows the time evolution of $\mathrm{H}$ and $\mathrm{V}$ at the pump and at locations $5 \mathrm{~km}, 50 \mathrm{~km}$ and $100 \mathrm{~km}$ upstream for times from 0 to $200 \mathrm{~s}$. (Recall that the higher reservoir is located $100 \mathrm{~km}$ upstream.) Figures 11 and 12 show $\mathrm{H}$ and $\mathrm{V}$ along the entire upstream portion of the pipeline at the selected times of 0, 5, 50, 100, 105, 150 and $200 \mathrm{~s}$ after the trip.

The $x=0 \mathrm{~km}$ plot shows that now there is an initial jump in head of $100 \mathrm{~m}$ on the upstream side of the pump - from $100 \mathrm{~m}$ to $200 \mathrm{~m}$. (Again, this is what the Joukowski formula predicts from the assumed instantaneous change in fluid velocity at the pump.) The head, and therefore also the pressure, then continues to rise at the pump in an almost linear fashion with time until $t=200 \mathrm{~s}$, when the reflected pressure pulse from the upstream reservoir reaches the pump. The total increase in head by $200 \mathrm{~s}$ is a little over $200 \mathrm{~m}$, corresponding to a pressure increase of some $2 \mathrm{MPa}$. The reason for this 
Figure 7: Long pipeline example. $\mathrm{H}$ and $\mathrm{V}$ versus $\mathrm{t}$ for downstream locations $x=0,5,50,100 \mathrm{~km}$.
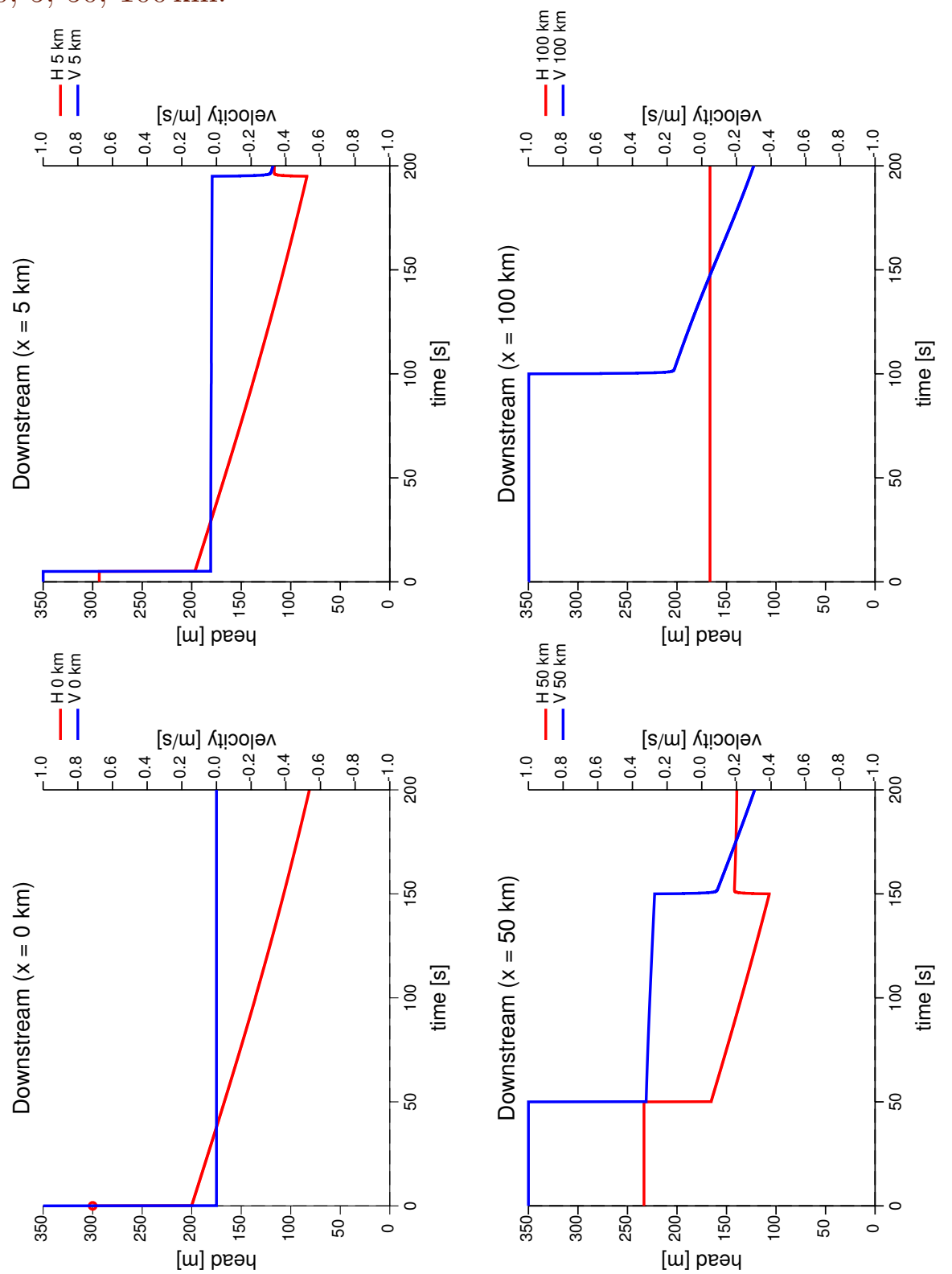
Figure 8: Long pipeline example. $\mathrm{H}$ and $\mathrm{V}$ versus $\mathrm{x}$ of downstream locations at $\mathrm{t}=0,5,50,100 \mathrm{~s}$. The dashed green line represents a simple ground elevation topography.
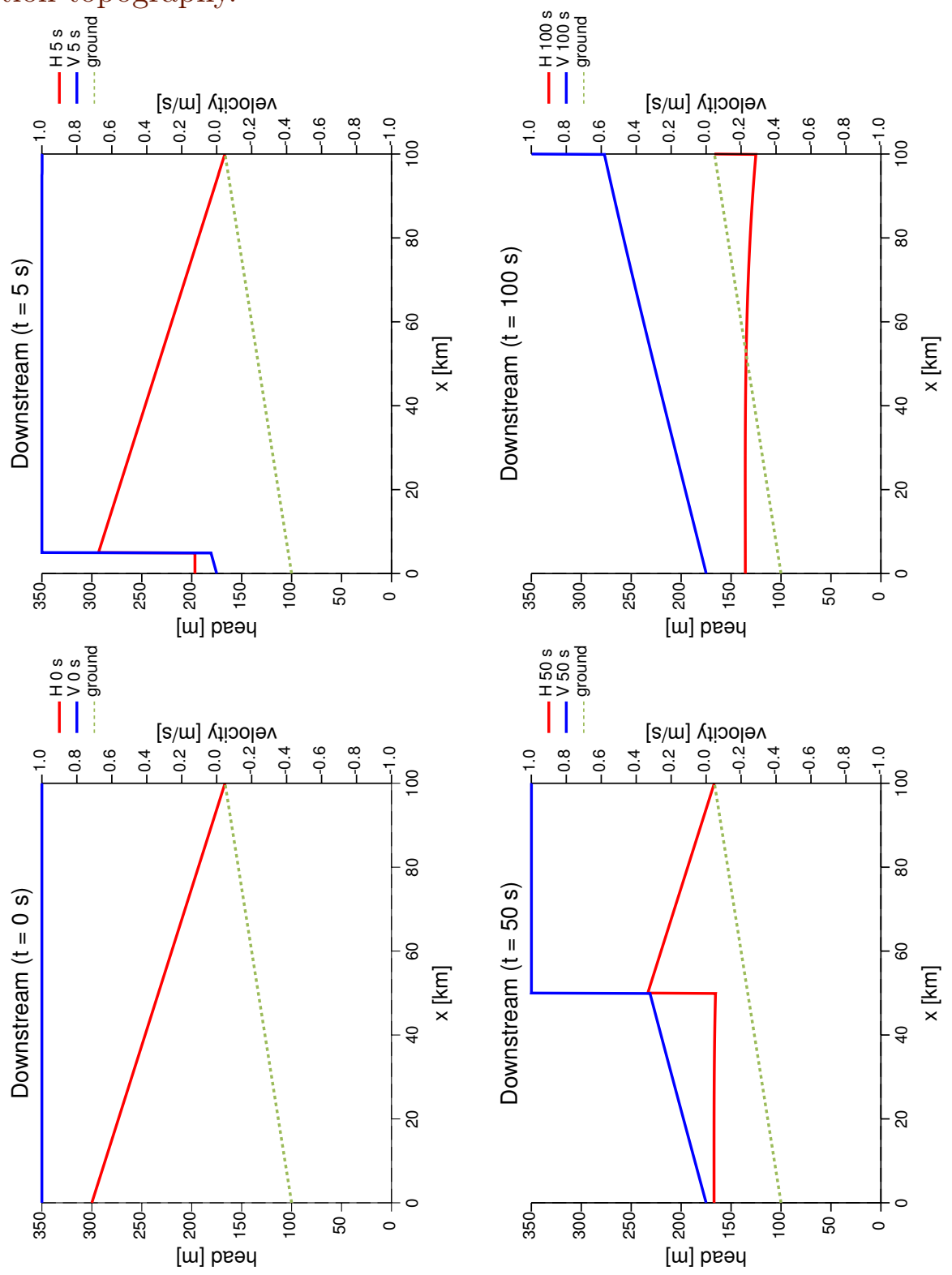
Figure 9: Long pipeline example. $\mathrm{H}$ and $\mathrm{V}$ versus $\mathrm{x}$ of downstream locations at $t=105,150,200 \mathrm{~s}$. The dashed green line represents a simple ground elevation topography.

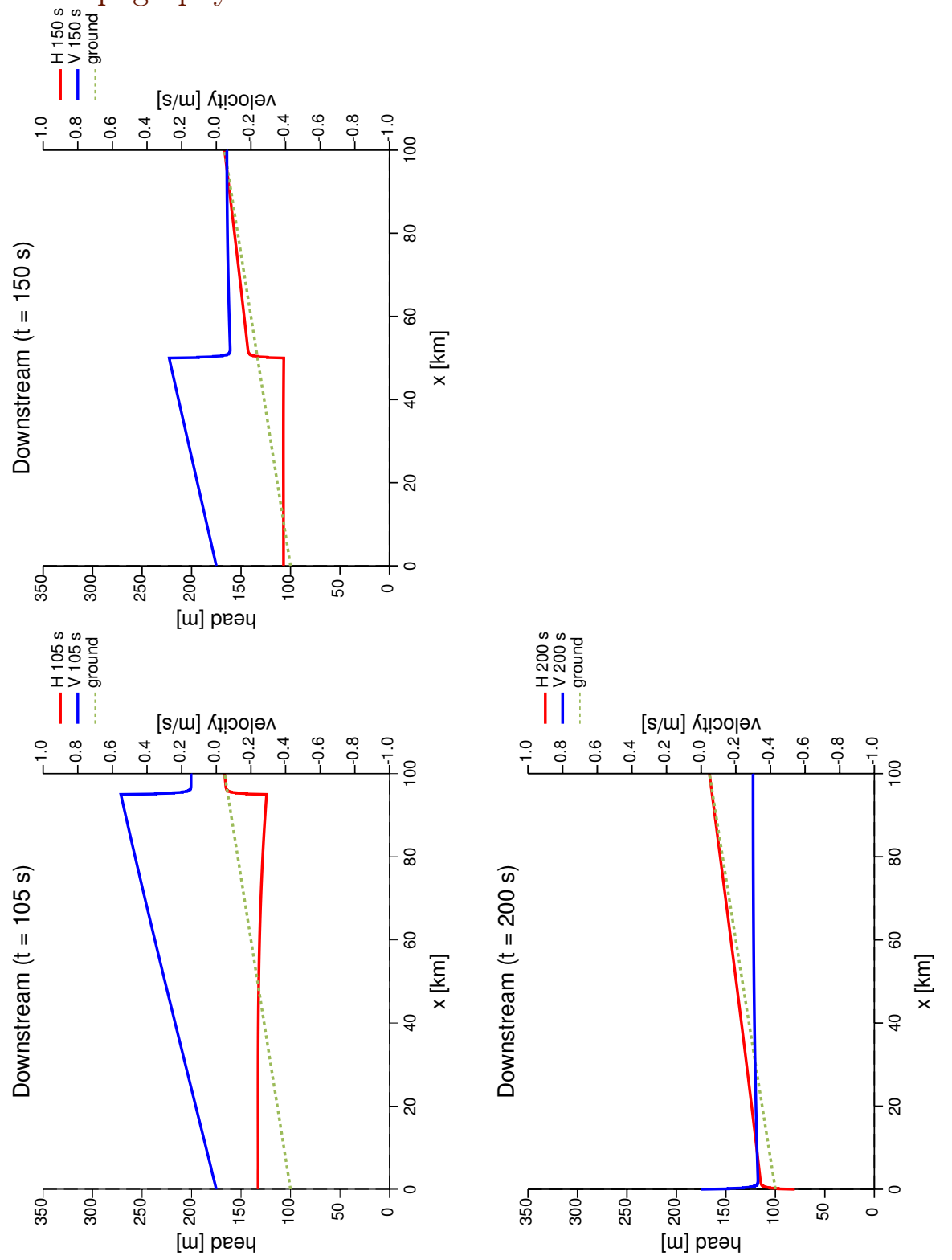


Figure 10: Long pipeline example. $\mathrm{H}$ and $\mathrm{V}$ versus $\mathrm{t}$ for upstream locations $x=0,5,50,100 \mathrm{~km}$.

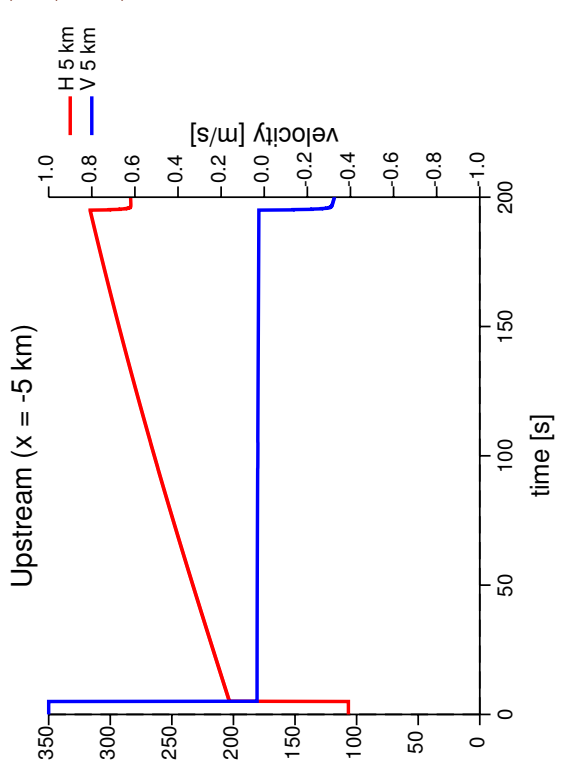

[u] peəu

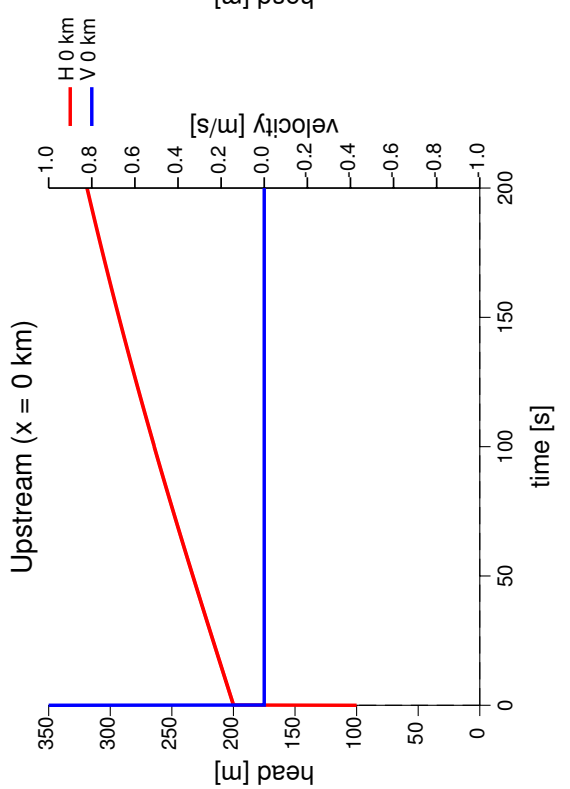

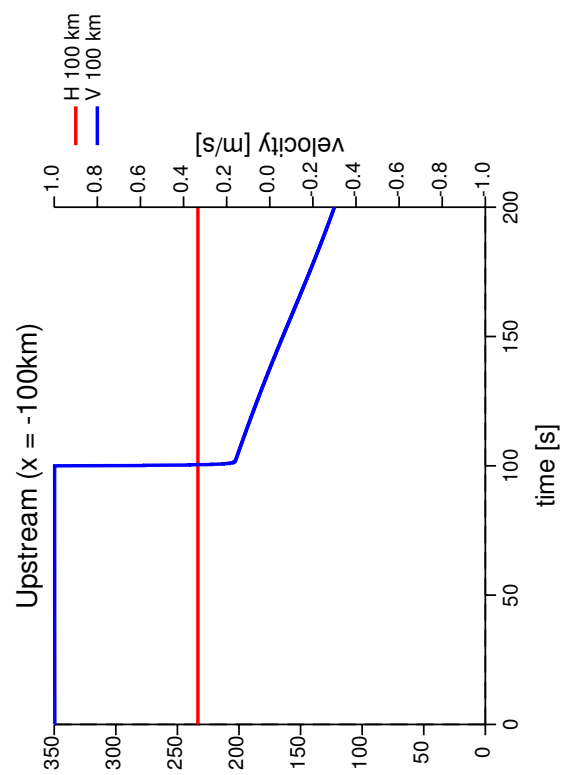

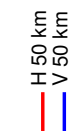

[u] реәч

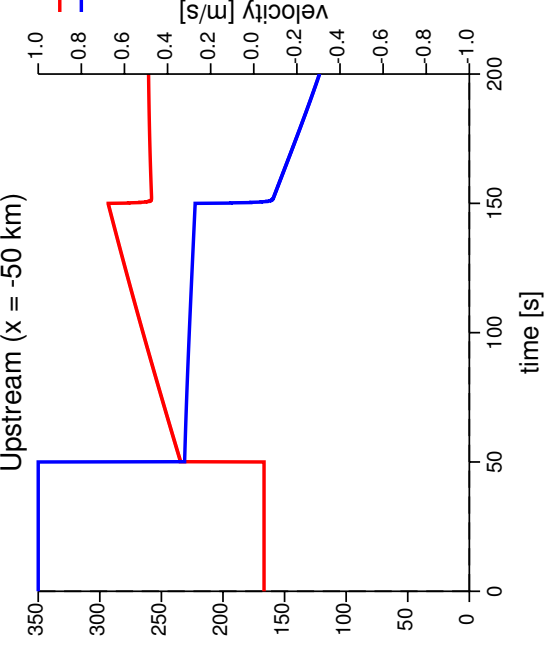

[u] peəy 
Figure 11: Long pipeline example. $\mathrm{H}$ and $\mathrm{V}$ versus $\mathrm{x}$ of upstream locations at $\mathrm{t}=0,5,50,100 \mathrm{~s}$.
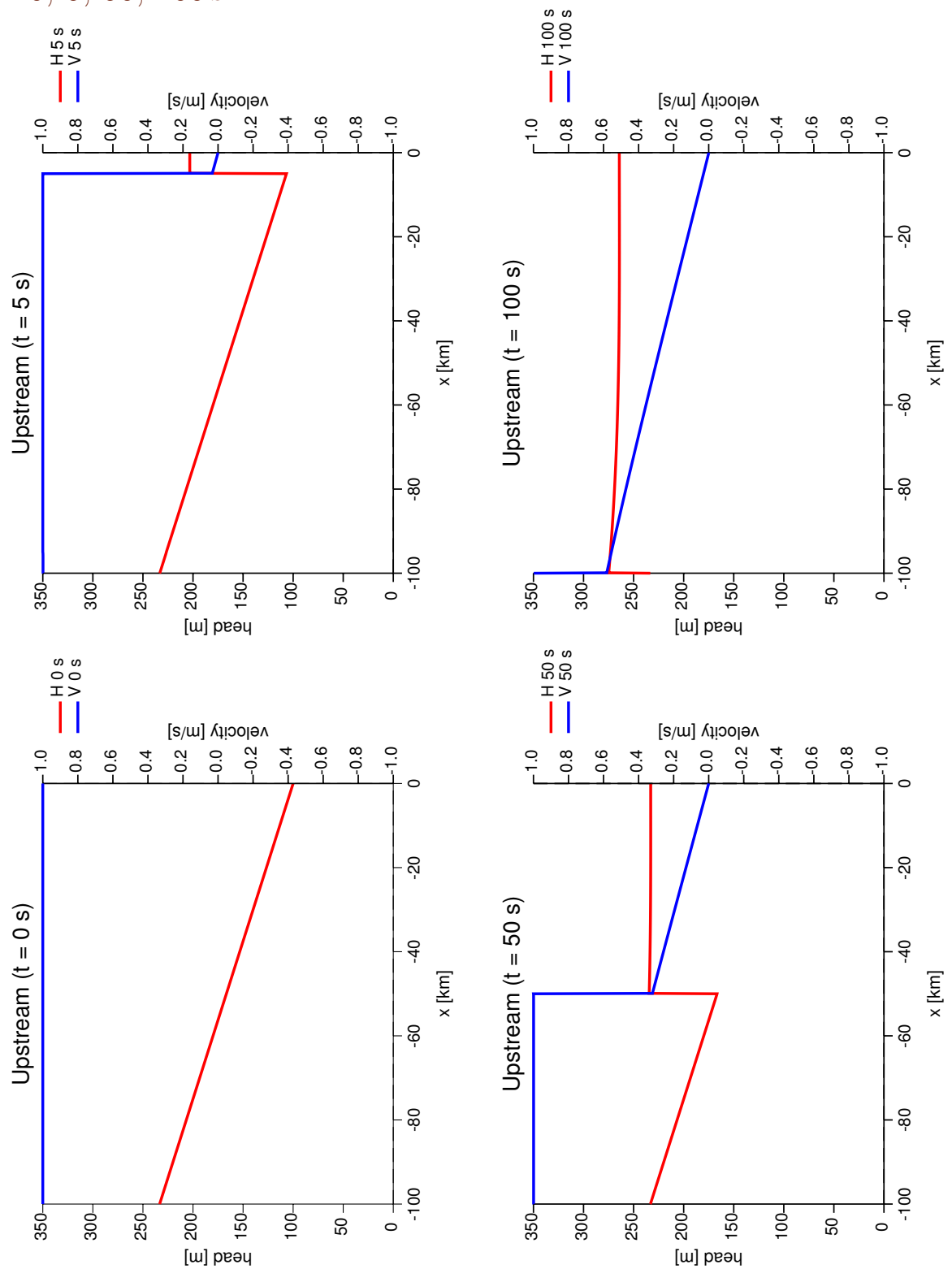
Figure 12: Long pipeline example. $\mathrm{H}$ and $\mathrm{V}$ versus $\mathrm{x}$ of upstream locations at $\mathrm{t}=105,150,200 \mathrm{~s}$.
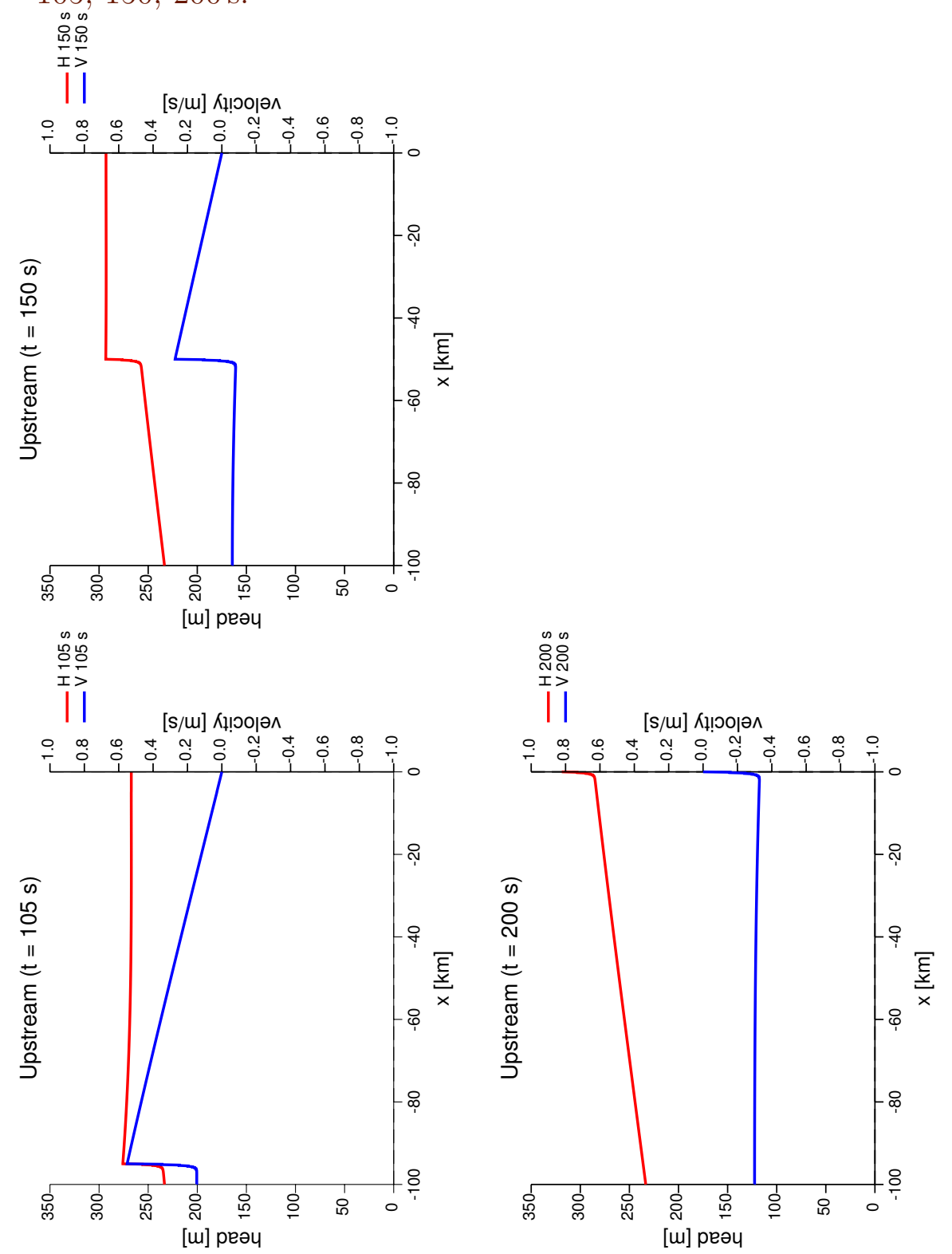
continuing rise in head, over that predicted by Joukowski, is similar to that for the continuing fall in head on the downstream side. The upstream travelling pulse initiated by the pump trip and valve closure is reduced in magnitude by frictional effects, so that it is increasingly unable to completely halt the fluid stream. Thus the fluid continues moving in the positive direction at, for example, a velocity of about 0.03 and $0.3 \mathrm{~ms}^{-1}$ at 5 and $50 \mathrm{~km}$ upstream respectively once the initial travelling pulse has passed these locations. The flow operates in an opposite fashion to that in the downstream case, where now fluid elements move closer to those fluid elements in front of them. Thus, the fluid is compressing itself, and so we expect an ongoing increase in pressure behind the pulse. This is seen in the $x=5 \mathrm{~km}$ and $x=50 \mathrm{~km}$ upstream plots of Figure 10.

At $\mathrm{t}=100 \mathrm{~s}$, the upstream travelling pulse reaches the upper reservoir, whose head is assumed to be constant at $233.3 \mathrm{~m}$. As Figure 11 shows, the head of the fluid, which is almost uniform throughout the pipe behind the pulse, overshoots the reservoir head by almost $50 \mathrm{~m}$. This causes another instantaneous change in fluid velocity, this time at the reservoir (supposing that air does not enter the pipe at the reservoir), and a reflected negative pulse travels back towards the pump. This pulse now reduces the head in the pipe, and further reduces the fluid velocity in the forward direction, until the fluid flow reverses in direction. At $t=200 \mathrm{~s}$, Figure 12 shows that just as the reflected pulse returns to the pump, there is a uniform rising hydraulic grade line from the reservoir to the pump, which is opposite to the original grade line, and there is a reverse flow in the pipe, that is, towards the reservoir.

Unlike for the downstream case, the danger on the upstream side of the pump mainly arises from high fluid pressure transients associated with the initial travelling pulse. These pressure transients may also cause mechanical damage to the pipe and associated fittings. 


\subsection{A short pipeline example}

As discussed in the previous subsection, the additional fall in head at the pump over that predicted by a straightforward application of the Joukowski result in the downstream case - or the additional rise in head in the upstream case - is largely due to the time it takes for the reflected pressure pulse to arrive back at the pump. This depends upon the length of the pipeline. To explore this a little further, we also consider an example of a shorter pipeline. In this example, all configuration parameters are as before, except that the pipeline now only extends $15 \mathrm{~km}$ downstream from the pump. Since the same flow velocity, pipe diameter and friction factor as before are assumed, the fall in steady state head along the pipe is reduced proportionally from $133.3 \mathrm{~m}$ to $20 \mathrm{~m}$, so the head at the downstream reservoir is $280 \mathrm{~m}$. We also assume that the trip now has a finite shutdown time of $10 \mathrm{~s}$. In the absence of any detailed knowledge of how the fluid velocity at the pump evolves over this shutdown period, we assume that the velocity profile at the pump $(x=0)$ falls linearly with time from $1 \mathrm{~ms}^{-1}$ at $t=0$ to rest at $t=10 \mathrm{~s}$.

Figure 13 shows the minimum head envelopes $15 \mathrm{~s}$ and $20 \mathrm{~s}$ after the trip event, and the maximum head envelope is for $40 \mathrm{~s}$ from the trip. The figure also shows two simple ground elevation topographies which start from $z=100 \mathrm{~m}$ at the pump and go to $z=280 \mathrm{~m}$ at the reservoir. It takes $40 \mathrm{~s}$ from the start of the trip event until the trailing edge of the reflected pressure pulse returns to the pump. In this example, the steady state hydraulic grade line drops $20 \mathrm{~m}$ over the $15 \mathrm{~km}$ of the pipe. The Joukowski fall in head is again $100 \mathrm{~m}$ (from $300 \mathrm{~m}$ to $200 \mathrm{~m}$ ), and the subsequent additional fall in the head at the pump $(x=0)$ is only a further $17 \mathrm{~m}$. As seen in the figure, the minimum head curve after $20 \mathrm{~s}$ is close to horizontal until $5 \mathrm{~km}$ from the reservoir, when it starts to rise to meet the fixed head of $280 \mathrm{~m}$ at the reservoir. Note that $5 \mathrm{~km}$ is half the width of the travelling pressure pulse. Thus, this would seem to be in accord with the spirit of Thorley's construction of the negative surgeline described in Section 2, at least for such relatively short pipes. 
Figure 13: The hydraulic grade line (HGL) and the maximum and minimum downstream head envelopes for a short pipeline of length $15 \mathrm{~km}$. The trip event is modelled as taking place over $10 \mathrm{~s}$ with a linear velocity profile at the pump ramping down from $1 \mathrm{~ms}^{-1}$ to rest. The maximum head envelope shown is for the $40 \mathrm{~s}$ time period following the start of the trip event, corresponding to the time for the $10 \mathrm{~s}$ pressure pulse to travel to the reservoir and for its trailing edge to be reflected back to the pump. Minimum head envelopes are shown for time periods of $15 \mathrm{~s}$ and $20 \mathrm{~s}$ after the trip. (The minimum head over the $40 \mathrm{~s}$ after the trip is not noticeably different from that over $20 \mathrm{~s}$.) The dashed lines represent two simple ground elevation topographies.

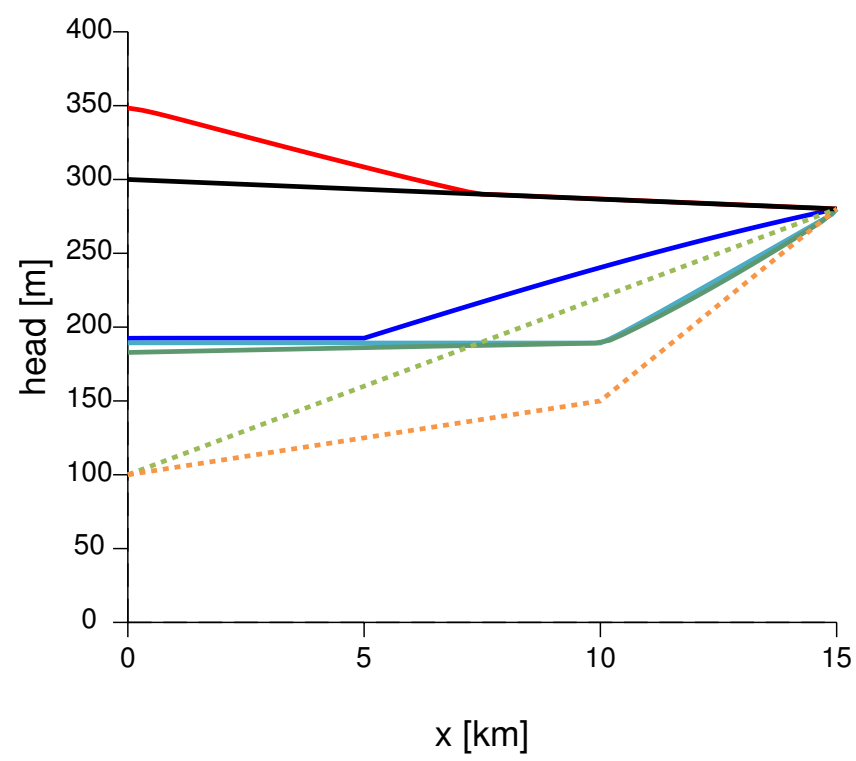

- $\mathrm{HGL}$

- H max. 40s $-\mathrm{H}$ min. $40 \mathrm{~s}$ $-\mathrm{H}$ min. $20 \mathrm{~s}$ $-\mathrm{H}$ min. $15 \mathrm{~s}$ - ground-A .... ground-B 
Considering the ground topography, denoted as ground-A in the figure, we see that at some time between $15 \mathrm{~s}$ and $20 \mathrm{~s}$ the minimum head curve drops below the elevation line. So, as for the long pipe example above, some surge protection would be required. However, for a different topography, such as that depicted by ground-B, the minimum head curve is above the elevation line for the entire length of the pipe. As the minimum head curve over $40 \mathrm{~s}$ is not noticeably different to that for $20 \mathrm{~s}$, we conclude that surge protection is not needed, at least based on what occurs in the first $40 \mathrm{~s}$ after the trip.

In this case the maximum head (positive surgeline) exceeds the hydraulic grade line from the pump at $x=0 \mathrm{~km}$ to $x=7.5 \mathrm{~km}$. The maximum head at the pump is $350 \mathrm{~m}$, some $50 \mathrm{~m}$ above the steady state hydraulic grade line at the pump. This increase in the maximum pressure may be a problem in practice, as it corresponds to a positive pressure surge which may cause damage to the pipeline or the pump if this pressure is outside their safe operating limits.

\subsection{An approximation to the additional fall in head at the pump}

In the examples discussed in the preceding two subsections, a close examination of the plots shows a number of consistent features of the behaviour of $\mathrm{H}$ and $\mathrm{V}$ behind the surge pulse. Restricting ourselves to the period of the initial forward transit of the pulse, that is, before there has been any reflections from the reservoirs, we observe that:

- $\mathrm{H}(x, t)$ is approximately horizontal, that is, independent of $x$, and falls linearly in time;

- $\mathrm{V}(\mathrm{x}, \mathrm{t})$ is approximately linear in $\mathrm{x}$, and constant in time.

It would be helpful to try to demonstrate these behaviours based on some theoretical considerations. If we could do this, then in the light of the first 
observation, we potentially have some frictional correction of the Joukowski formula.

To make progress, let us again assume an instantaneous trip and consider what then happens downstream. The trip results in a pulse of discontinuity in $\mathrm{H}$ and $\mathrm{V}$ travelling at a speed of a. Figure 14 represents this pulse in $x$ - $t$ space as the characteristic line $x=a t$, or $\xi=0$ in the notation introduced in Section 5. This line divides $x$ - $t$ space into two regions, representing points behind the pulse and points in front of the pulse. Let $\mathrm{P}$ be a point on this line. We consider how $\mathrm{H}$ and $\mathrm{V}$ are related on either side of this line in $\mathrm{x}$ $\mathrm{t}$ space near $\mathrm{P}$. Consider points $\mathrm{P}^{\prime}$ and $\mathrm{P}^{\prime \prime}$ as in Figure 14 which lie on a line $\eta=$ constant. As in our derivation of Joukowski's formula in Subsection 5.2, we let $\mathrm{P}^{\prime} \rightarrow \mathrm{P}$ from in front of the pulse, and $\mathrm{P}^{\prime \prime} \rightarrow \mathrm{P}$ from behind the pulse, and apply (15) to again obtain

$$
\lim _{\mathrm{P}^{\prime \prime} \rightarrow P}\left(H-\frac{a}{g} V\right)=\lim _{P^{\prime} \rightarrow P}\left(H-\frac{a}{g} V\right),
$$

since the friction integral has a limiting value of 0 as the distance $\mathrm{P}^{\prime} \mathrm{P}^{\prime \prime} \rightarrow 0$. The left hand limit is from behind the pulse, and the right hand one is from in front of the pulse.

In front of the pulse, the steady state distributions of $\mathrm{H}$ and $\mathrm{V}$ apply. These correspond to

$$
\mathrm{V}=\mathrm{V}_{0}, \quad \mathrm{H}=\mathrm{H}_{0}-\frac{f \mathrm{~V}_{0}^{2}}{2 \mathrm{gD}} \mathrm{x}
$$

where $\mathrm{V}_{0}$ and $\mathrm{H}_{0}$ are constants (equal to $1 \mathrm{~ms}^{-1}$ and $300 \mathrm{~m}$ in the examples of the preceding two subsections). Thus

$$
H-\frac{a}{g} V=H_{0}-\frac{f V_{0}^{2}}{2 g D} x-\frac{a}{g} V_{0},
$$

where here, and from now on in this subsection, $\mathrm{H}$ and $\mathrm{V}$ denote the limiting values at a point $P$ on the characteristic $x=a t$ as it is approached from behind the pulse. 
Next, apply (14) along the characteristic $x=a t$, using the limiting values for $\mathrm{H}$ and $\mathrm{V}$ from behind the pulse. Supposing that behind the pulse the velocity $\mathrm{V}$ is small compared to $\mathrm{V}_{0}$, as it certainly will be for small time and close to the pump, then we may reasonably neglect the frictional integral since $f$ is usually small and the integral involves $V^{2}$. Hence we conclude that

$$
\mathrm{H}+\frac{\mathrm{a}}{\mathrm{g}} \mathrm{V}=\text { constant }
$$

behind the pulse. Thus, behind the pulse,

$$
H=H_{0}^{\prime}-\frac{f V_{0}^{2}}{4 g D} x \quad \text { and } \quad V=V_{0}^{\prime}+\frac{f V_{0}^{2}}{4 a D} x,
$$

for some new constants $\mathrm{H}_{0}^{\prime}$ and $\mathrm{V}_{0}^{\prime}$, whose precise form will not concern us for the moment.

Recall the simplified water hammer equations (11) and (12). Consistent with our neglect of the frictional terms behind the pulse, that is in the region $x<$ at

$$
\begin{aligned}
& g \frac{\partial H}{\partial x}+\frac{\partial V}{\partial t}=0 \\
& \frac{a^{2}}{g} \frac{\partial V}{\partial x}+\frac{\partial H}{\partial t}=0
\end{aligned}
$$

We finally observe that

$$
H=H_{0}^{\prime}-\frac{a f V_{0}^{2}}{4 g D} t \text { and } V=V_{0}^{\prime}+\frac{f V_{0}^{2}}{4 a D} x
$$

are solutions of these equations, which satisfy the boundary conditions (22) at $x=$ at. The boundary conditions $\mathrm{V}=0$ at $\mathrm{x}=0$ and $\mathrm{H}=\mathrm{H}_{0}-\Delta \mathrm{H}_{\mathrm{J}}$ at $\mathrm{t}=0+$, where $\Delta \mathrm{H}_{\mathrm{J}}=(\mathrm{a} / \mathrm{g}) \mathrm{V}_{0}$ is the instantaneous fall in head given by the Joukowski formula, then give us the values for $\mathrm{H}_{0}^{\prime}$ and $\mathrm{V}_{0}^{\prime}$. Thus,

$$
\begin{aligned}
& H=H_{0}-\Delta H_{J}-\frac{a f V_{0}^{2}}{4 g D} t \\
& V=\frac{f V_{0}^{2}}{4 a D} x .
\end{aligned}
$$


Figure 14: Derivation of an extended Joukowski relation for the discontinuities in head and velocity across a travelling pulse.

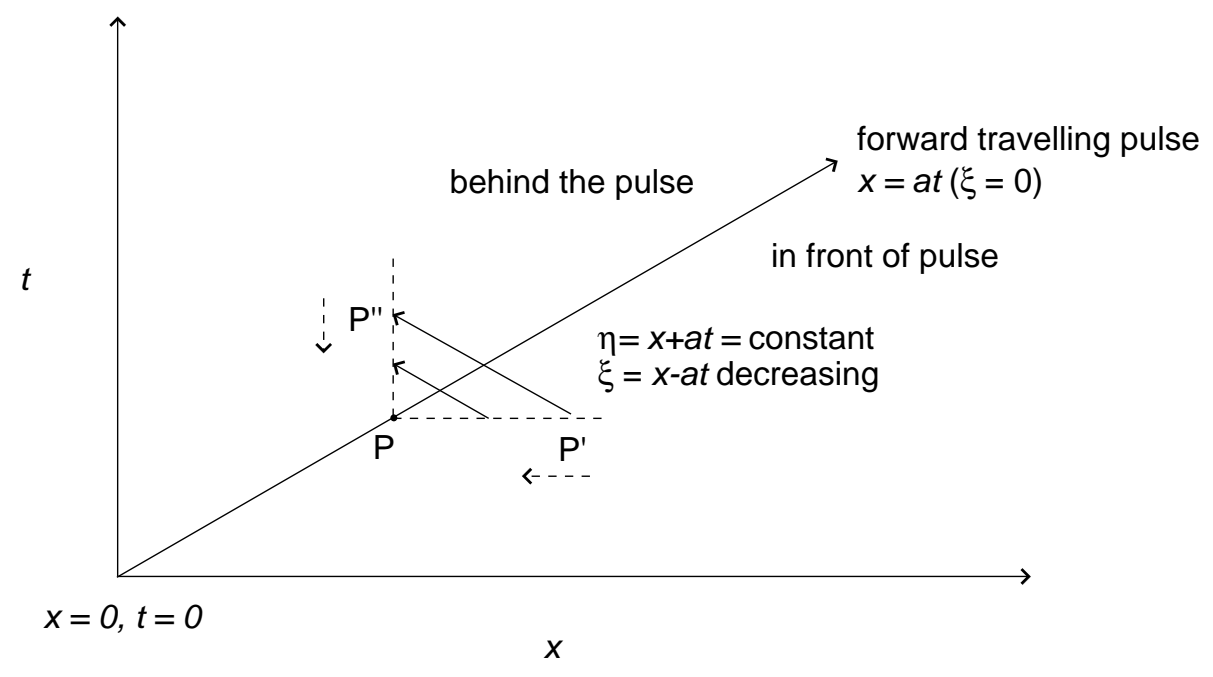

These approximate formulae support the observations listed at the start of this subsection. The first equation for $\mathrm{H}$ can be thought of as providing a frictional correction of the Joukowski result; and, as already mentioned in our discussion of the examples (Subsections 6.1, 6.2), it shows that this frictional correction depends on time. For the long pipeline example, a comparison of these formulae and the numerical results shows quite good agreement to what is happening behind the surge pulse, even up until $100 \mathrm{~s}$, when the pulse reaches the reservoir. These formulae are based on neglecting frictional effects behind the pulse (but accounting for them in front of the pulse). We expect this assumption to become less valid as the pulse advances in space and the velocity behind it increases. 


\section{Conclusions}

The group was successful in considering the major points in this problem. We were able to show that the Joukowski formula for predicting the change in head corresponding to a sudden change in flow velocity was correctly formulated and to understand and mimic the preliminary pipeline design process of constructing a surgeline where the minimum head was determined from the head drop at the pump given by the Joukwski formula and assuming an instantaneous cessation of flow immediately following a pump-trip event. Intersections of this surgeline with the ground surface indicate the need for surge protection.

The water-hammer equations were also solved to consider some different scenarios for a pump trip event and to determine surgelines for comparison with those obtained via the prelimary design process. These simulations showed that while the Joukowski formula correctly predicts the initial head drop (or rise for the upstream case), there is a further trailing drop in head because of the friction forces in the pipeline that work against the stopping of the flow. This additional drop in head is mentioned as very slight in the rising-main example of Thorley [8, Section 2.2.1]. However, it becomes more significant as the length of the pipeline increases, and is very noticeable for long pipelines because its final magnitude is related to the time for the water-hammer pressure pulse to travel from the pump to the reservoir and then back to the pump. It will also be most pronounced for high friction flows.

In subsequent work, we obtained a simple formula that gives a good approximation to this extra fall, and so suggest a modified formula for the head drop at the pump at time $t$ after a pump trip event that includes this frictional correction, namely

$$
\Delta H=-\frac{a V}{g}-\frac{f V^{2} a}{4 g D} t=-\frac{a V}{g}\left(1+\frac{f V}{4 D} t\right) .
$$

This formula may be useful for obtaining a better estimate of the surgeline 
in preliminary designs of pipelines. In particular, the surgeline constructed at the preliminary design stage is that corresponding to the pipeline period $\mathrm{t}=2 \mathrm{~L} / \mathrm{a}$, the time at which the pressure surge returns to the pump(s), which implies a total head drop at the pump given by the Joukowski formula plus the frictional losses along the pipeline under normal operating conditions, that is,

$$
\Delta \mathrm{H}=-\frac{\mathrm{aV}}{\mathrm{g}}-\frac{\mathrm{fV}^{2} \mathrm{~L}}{2 \mathrm{gD}} .
$$

For short pipelines the frictional correction may be sufficiently small to neglect but we suggest that its inclusion may be worthwhile for long pipelines.

The trailing pressure drop computed in this work may explain differences between a detailed design using WATHAM and an approximate design obtained using the Joukowski head change only. It is likely that the behaviour in the system during a pump-trip event is unaffected by the nature of the pumps and systems near the source and so while these are important in the design process, they are less so in determining surge pressures. In order to completely resolve all of these matters further, more targeted simulations would be necessary.

Acknowledgements This problem was presented at the MISG 2015 by SunWater. The team working on the problem throughout the MISG week included: Gabrielle Papale (SunWater representative), Yvonne Stokes, Graeme Hocking, Ed Green, Scott McCue, Tony Miller, John Thew, Tiong Tze, Mike Chen, Rebecca Tung, Glen Oberman, David Arnold, Saber Dini, Michael Jackson, David Shteiman.

\section{References}

[1] M. Hanif Chaudhry (2014) Applied Hydraulic Transients, 3rd ed., Springer; doi:10.1007/978-1-4614-8538-4. M165, M166, M173, M176 
[2] D.J. Korteweg (1878) Ueber die Fortpflanzungsgeschwindigkeit des Schalles in elastischen Rohren. (On the velocity of propagation of sound in elastic tubes.). Annalen der Physik und Chemie, New Series 5, 525-542 (in German); doi:10.1002/andp.18782411206. M166

[3] H. Lamb (1932) Hydrodynamics, 6th ed., Cambridge University Press, Cambridge. M166

[4] H.-J. Lüdecke and B. Kothe (2006) Water Hammer, in KSB Know-how, Volume 1, KSB Aktiengesellschaft Communications, Halle (Germany). Available at https://www. ksb.com/blob/7228/b03ed4dd6aa0139a876090d66fe3b9f2/

dow-know-how1-water-hammer-data. M171

[5] R. Skalak (1957) Longitudinal impact of a semi-infinite circular elastic bar, ASME Journal of Applied Mechanics 24, 59-64. M166

[6] V.L. Streeter and E.B. Wylie (1983) Fluid Mechanics, First SI Metric Edition, McGraw Hill Civil and Mechanical Engineering Series. M167, M176

[7] P/K. Swamee and A.K. Jain (1976) Explicit Equations for Pipe-Flow Problems, J. Hydr. Div., Proc. ASCE, pp 657-664. M176

[8] A.R.D. Thorley (2004) Fluid transients in pipeline systems, 2nd ed., Professional Engineering Publishing, London. M165, M170, M171, M201

\section{Author addresses}

1. Y. M. Stokes, School of Mathematical Sciences, The University of Adelaide, Adelaide, SA 5005, Australia.

mailto:yvonne.stokes@adelaide.edu.au

2. A. Miller, School of Computer Science, Engineering and Mathematics, Flinders University, Bedford Park, SA 5042, Australia. 
mailto:tony.miller@flinders.edu.au

3. G. Hocking, School of Engineering and Information Technology, Murdoch University, Murdoch, WA 6150, Australia.

mailto:g.hocking@murdoch.edu.au 